Marquette University

e-Publications@Marquette

6-1-2018

\title{
Testing the Boundaries of the Double Auction: The Effects of Complete Information and Market Power
}

Erik O. Kimbrough

Chapman University

Andrew Smyth

Marquette University, andrew.smyth@marquette.edu

Accepted version. Journal of Economic Behavior \& Organization, Vol. 150 (June 2018): 372-396.

DOI. (C) 2018 Elsevier B.V. Used with permission. 
Marquette University

\section{e-Publications@Marquette}

\section{Economics Faculty Research and Publications/College of Business Administration}

This paper is NOT THE PUBLISHED VERSION; but the author's final, peer-reviewed manuscript. The published version may be accessed by following the link in the citation below.

Journal of Economic Behavior \& Organization, Vol. 150, June (2018): 372-396. DOI. This article is (C) Elsevier and permission has been granted for this version to appear in e-Publications@Marquette. Elsevier does not grant permission for this article to be further copied/distributed or hosted elsewhere without the express permission from Elsevier.

\section{Testing the boundaries of the double auction: The effects of complete information and market power}

Erik O. Kimbrough

Smith Institute for Political Economy and Philosophy, Chapman University, United States

Department of Economics, Simon Fraser University, Canada

Andrew Smyth

Department of Economics, Marquette University, United States

\section{Abstract}

We report boundary experiments testing the robustness of price convergence in double auction markets for non-durable goods in which there is extreme earnings inequality at the competitive equilibrium (CE). Following up on a conjecture by Smith (1976a), we test whether the well-known equilibrating power of the double auction institution is robust to the presence of complete information about traders' values and costs and the presence of symmetric market power. We find that complete 
information is insufficient to impede convergence to CE prices; however, introducing market power consistently causes prices to deviate from the $\mathrm{CE}$, whether or not subjects possess complete information. Our design highlights the value of boundary experiments in understanding how market institutions shape behavior, and our findings help delineate the limits of the double auction institution to generate competitive outcomes.

\title{
Keywords
}

Double auction, Market power, Institutions, Information, Experimental economics

\begin{abstract}
A market, then, is theoretically perfect only when all traders have perfect knowledge of the conditions of supply and demand, and the consequent ratio of exchange [...] So essential is a knowledge of the real state of supply and demand to the smooth procedure of trade and the real good of the community, that I conceive it would be quite legitimate to compel the publication of any requisite statistics.
\end{abstract}

W.S. Jevons (1871)

If the reader bristles at the acceptance of assumptions such as perfect knowledge [...] He is right if he believes these extreme assumptions are not necessary to the existence of competition [...] The reason for not stating the weakest assumptions (necessary conditions) for competition is that they are difficult to formulate, and in fact are not known precisely.

G.L. Stigler (1966)

One of the most prominent, replicable, empirical properties of the double auction competitive price mechanism is its rapid convergence to the supply and demand equilibrium under the condition of incomplete information [...] It might be supposed that under complete information, where each agent is informed of the value and cost functions of other agents, market convergence would improve, or at minimum not be worse [...] [T] here is at least one class of crucial experiments for which this proposition must be rejected, namely the class in which all the exchange surplus is obtained by the buyers (or sellers) at the equilibrium price.

V.L. Smith (1980)

\section{Introduction}

Probably the most widely replicated experiment in economics shows the power of the continuous double auction institution to generate competitive equilibrium (CE) allocations of non-durable goods. Beginning with Smith (1962), experiments have shown that even markets composed of inexperienced traders, possessing incomplete information about supply and demand, rapidly converge to the CE after only a few market repetitions. This striking result has been subjected to a number of powerful stress tests, yet the convergence properties of the double auction remain robust. In particular, convergence is robust to variation in the number of buyers and sellers (e.g. this number need only be greater than two; see Smith, 1981, Smith, Williams, 1990), to within-session changes in the supply and demand arrays, and to both computerized and hand-run implementation; see (Davis and Holt, 1993) for a survey of the classic literature. 
In a particularly rigorous stress test, Smith (1965) provides evidence that equilibrium is still achieved in a so-called "swastika" supply and demand array. In such a market (see Fig. 1), all the exchange surplus goes to one side of the market at the CE price. ${ }^{1}$ As Smith (1982b) and Holt et al. (1986) note, such a supply and demand environment provides a uniquely stringent test of the equilibrating capabilities of the double auction since there exists a continuum of prices that support efficient, though noncompetitive, allocations. Nevertheless, Smith, 1965, Smith, 1982b, and Holt et al. (1986) all report that such markets converge to the CE. This result has also been replicated in a number of studies, all of which (to the best of our knowledge) are summarized in Table 1, which provides references and catalogues the institutional details of each session.

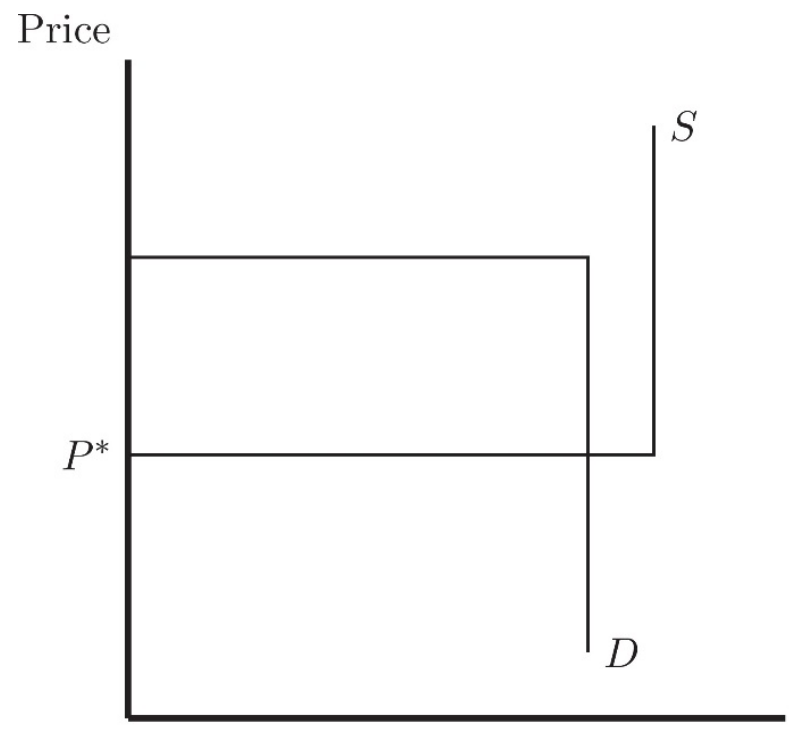

Fig. 1. Market with all surplus obtained by buyers at the CE.

Units

Table 1. Summary of previous research.

\begin{tabular}{|c|c|c|c|c|c|c|c|c|c|}
\hline Reference & Name & $\begin{array}{l}\text { Complete } \\
\text { Information }\end{array}$ & $\begin{array}{l}\text { Hand- } \\
\text { run }\end{array}$ & Periods & $\begin{array}{l}\text { Excess } \\
\text { Supply }\end{array}$ & Units & $\begin{array}{l}\text { Buyers } \\
\& \\
\text { Sellers }\end{array}$ & Commission & $\begin{array}{l}\text { Closing } \\
\text { Rule }\end{array}$ \\
\hline \multirow[t]{6}{*}{ Smith (1965) } & $\begin{array}{l}\text { Session } \\
1\end{array}$ & No & Yes & 6 & Yes (2) & Single & $11 \& 13$ & $\$ 0.05$ & Soft \\
\hline & $\begin{array}{l}\text { Session } \\
2\end{array}$ & No & Yes & 4 & Yes (2) & Single & $11 \& 13$ & $\$ 0.05$ & Soft \\
\hline & $\begin{array}{l}\text { Session } \\
3\end{array}$ & No & Yes & 4 & Yes (5) & Single & $11 \& 16$ & $\$ 0.05$ & Soft \\
\hline & $\begin{array}{l}\text { Session } \\
4\end{array}$ & No & Yes & 4 & Yes (5) & Single & $11 \& 16$ & $\$ 0.05$ & Soft \\
\hline & $\begin{array}{l}\text { Session } \\
5\end{array}$ & No & Yes & 4 & Yes (8) & Single & $11 \& 19$ & $\$ 0.05$ & Soft \\
\hline & $\begin{array}{l}\text { Session } \\
6\end{array}$ & No & Yes & 4 & Yes (8) & Single & $11 \& 19$ & $\$ 0.05$ & Soft \\
\hline \multirow[t]{6}{*}{ Smith (1976b) } & Exp. 1 & No & Yes & 4 & Yes (5) & Single & $11 \& 16$ & $\$ 0.05$ & Soft \\
\hline & Exp. 2 & No & Yes & 4 & Yes (5) & Single & $11 \& 16$ & $\$ 0.05$ & Soft \\
\hline & Exp. 4 & Yes & Yes & 4 & Yes (5) & Single & $11 \& 16$ & $\$ 0.05$ & Soft \\
\hline & Exp. 5 & No & Yes & 4 & Yes (8) & Single & $11 \& 19$ & $\$ 0.05$ & Soft \\
\hline & Exp. 6 & No & Yes & 4 & Yes (8) & Single & $11 \& 19$ & $\$ 0.05$ & Soft \\
\hline & Exp. 7 & Yes & Yes & 4 & Yes (8) & Single & $11 \& 19$ & $\$ 0.05$ & Soft \\
\hline
\end{tabular}




\begin{tabular}{|c|c|c|c|c|c|c|c|c|c|}
\hline Smith (1976a) & $\begin{array}{l}\text { Figure } \\
7 a\end{array}$ & No & Yes & 4 & Yes (5) & Single & $11 \& 19$ & $\$ 0.05$ & Soft \\
\hline \multirow[t]{2}{*}{ Smith (1980) } & $\begin{array}{l}\text { Figure } \\
5 d\end{array}$ & No/Yes & Yes & $2 / 2$ & Yes (7) & Mult. & $2 \& 3$ & $\$ 0.05$ & Soft \\
\hline & $\begin{array}{l}\text { Figure } \\
6 d\end{array}$ & No/Yes & Yes & $3 / 2$ & Yes (8) & Single & $11 \& 19$ & $\$ 0.05$ & Soft \\
\hline Smith (1982a) & Figure 4 & No & No & $5 / 5$ & $\begin{array}{l}\text { Yes/No } \\
\text { (5) }\end{array}$ & Mult. & $4 \& 4$ & $\$ 0.10$ & Hard \\
\hline Holt et al. (1986) & Exp. 1 & No & No & $5 / 5$ & $\begin{array}{l}\text { No/Yes } \\
\text { (5) }\end{array}$ & Mult. & $4 \& 4$ & $\$ 0.10^{a}$ & Hard \\
\hline \multirow[t]{8}{*}{$\begin{array}{l}\text { Smith and } \\
\text { Williams (1990) }\end{array}$} & $\begin{array}{l}\text { Exp. } \\
\text { S1x }\end{array}$ & No & No & $5 / 5$ & $\begin{array}{l}\text { Yes/No } \\
\text { (5) }\end{array}$ & Mult. & $4 \& 4$ & $\$ 0.10$ & Hard \\
\hline & $\begin{array}{l}\text { Exp. } \\
\text { S2x }\end{array}$ & No & No & $5 / 5$ & $\begin{array}{l}\text { No/Yes } \\
\text { (5) }\end{array}$ & Mult. & $4 \& 4$ & $\$ 0.10$ & Hard \\
\hline & $\begin{array}{l}\text { Exp. } \\
\text { S3x }\end{array}$ & No & No & $5 / 5$ & $\begin{array}{l}\text { Yes/No } \\
\text { (5) }\end{array}$ & Mult. & $4 \& 4$ & $\$ 0.10$ & Hard \\
\hline & $\begin{array}{l}\text { Exp. } \\
\text { S4x }\end{array}$ & No & No & $4 / 5$ & $\begin{array}{l}\text { No/Yes } \\
\text { (5) }\end{array}$ & Mult. & $4 \& 4$ & $\$ 0.10$ & Hard \\
\hline & $\begin{array}{l}\text { Exp. } \\
\text { S5x }\end{array}$ & No & No & $5 / 5$ & $\begin{array}{l}\text { Yes/No } \\
\text { (5) }\end{array}$ & Mult. & $4 \& 4$ & $\$ 0.10$ & Hard \\
\hline & $\begin{array}{l}\text { Exp. } \\
\text { S6x }\end{array}$ & No & No & $5 / 5$ & $\begin{array}{l}\text { No/Yes } \\
\text { (5) }\end{array}$ & Mult. & $4 \& 4$ & $\$ 0.10$ & Hard \\
\hline & $\begin{array}{l}\text { Exp. } \\
\text { S7x }\end{array}$ & No & No & 13 & Yes (5) & Mult. & $4 \& 4$ & $\$ 0.00$ & Hard \\
\hline & $\begin{array}{l}\text { Exp. } \\
\text { S8x }\end{array}$ & No & No & 6 & No (5) & Mult. & $4 \& 4$ & $\$ 0.00$ & Hard \\
\hline \multirow[t]{14}{*}{$\begin{array}{l}\text { Kachelmeier and } \\
\text { Shehata (1992) }\end{array}$} & $\begin{array}{l}\text { Market } \\
\text { A1 }\end{array}$ & No & Yes & $11 / 11$ & $\begin{array}{l}\text { No/Yes } \\
\text { (5) }\end{array}$ & Mult. & $4 \& 4$ & $\$ 0.00$ & Both \\
\hline & $\begin{array}{l}\text { Market } \\
\text { A2 }\end{array}$ & No & Yes & $11 / 11$ & $\begin{array}{l}\text { No/Yes } \\
\text { (5) }\end{array}$ & Mult. & $4 \& 4$ & $\$ 0.00$ & Both \\
\hline & $\begin{array}{l}\text { Market } \\
\text { A3 }\end{array}$ & No & Yes & $11 / 11$ & $\begin{array}{l}\text { No/Yes } \\
\text { (5) }\end{array}$ & Mult. & $4 \& 4$ & $\$ 0.00$ & Both \\
\hline & $\begin{array}{l}\text { Market } \\
\text { A4 }\end{array}$ & No & Yes & 11/11 & $\begin{array}{l}\text { No/Yes } \\
\text { (5) }\end{array}$ & Mult. & $4 \& 4$ & $\$ 0.00$ & Both \\
\hline & $\begin{array}{l}\text { Market } \\
\text { A5 }\end{array}$ & No & Yes & $11 / 11$ & $\begin{array}{l}\text { No/Yes } \\
\text { (5) }\end{array}$ & Mult. & $4 \& 4$ & $\$ 0.00$ & Both \\
\hline & $\begin{array}{l}\text { Market } \\
\text { B1 }\end{array}$ & No & Yes & $11 / 11$ & $\begin{array}{l}\text { No/Yes } \\
\text { (5) }\end{array}$ & Mult. & $4 \& 4$ & $\$ 0.00$ & Both \\
\hline & $\begin{array}{l}\text { Market } \\
\text { B2 }\end{array}$ & No & Yes & $11 / 11$ & $\begin{array}{l}\text { No/Yes } \\
\text { (5) }\end{array}$ & Mult. & $4 \& 4$ & $\$ 0.00$ & Both \\
\hline & $\begin{array}{l}\text { Market } \\
\text { B3 }\end{array}$ & No & Yes & $11 / 11$ & $\begin{array}{l}\text { No/Yes } \\
\text { (5) }\end{array}$ & Mult. & $4 \& 4$ & $\$ 0.00$ & Both \\
\hline & $\begin{array}{l}\text { Market } \\
\text { B4 }\end{array}$ & No & Yes & 11/11 & $\begin{array}{l}\text { No/Yes } \\
\text { (5) }\end{array}$ & Mult. & $4 \& 4$ & $\$ 0.00$ & Both \\
\hline & $\begin{array}{l}\text { Market } \\
\text { B5 }\end{array}$ & No & Yes & $11 / 11$ & $\begin{array}{l}\text { No/Yes } \\
\text { (5) }\end{array}$ & Mult. & $4 \& 4$ & $\$ 0.00$ & Both \\
\hline & $\begin{array}{l}\text { Market } \\
\text { C1 }\end{array}$ & Yes & Yes & 11/11 & $\begin{array}{l}\text { No/Yes } \\
\text { (5) }\end{array}$ & Mult. & $4 \& 4$ & $\$ 0.00$ & Both \\
\hline & $\begin{array}{l}\text { Market } \\
\text { C2 }\end{array}$ & Yes & Yes & 11/11 & $\begin{array}{l}\text { No/Yes } \\
\text { (5) }\end{array}$ & Mult. & $4 \& 4$ & $\$ 0.00$ & Both \\
\hline & $\begin{array}{l}\text { Market } \\
\text { C3 }\end{array}$ & Yes & Yes & 11/11 & $\begin{array}{l}\text { No/Yes } \\
\text { (5) }\end{array}$ & Mult. & $4 \& 4$ & $\$ 0.00$ & Both \\
\hline & $\begin{array}{l}\text { Market } \\
\text { C4 }\end{array}$ & Yes & Yes & $11 / 11$ & $\begin{array}{l}\text { No/Yes } \\
\text { (5) }\end{array}$ & Mult. & $4 \& 4$ & $\$ 0.00$ & Both \\
\hline
\end{tabular}




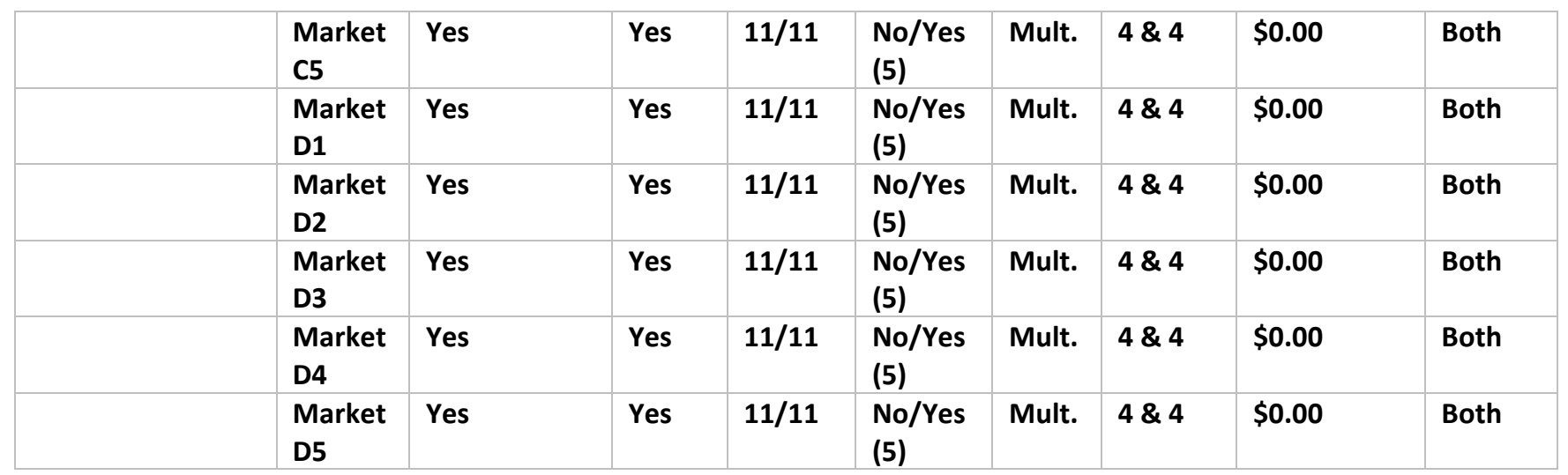

Notes: The table contains all "swastika" design experiments with paid subjects. A slash indicates switchover in information or excess supply to excess demand. In all cases except (Kachelmeier and Shehata, 1992), total available surplus was \$1.10. Bold text indicates that the session provided traders complete information on supply and demand in at least some of the trading periods. When the closing rule is listed as "Both", this is because there was a hard close, but if offers ceased before the time limit was reached, a soft closing rule was used instead.

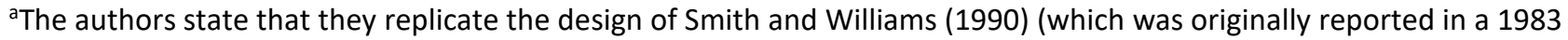
working paper), but they do not mention a commission value. We assume that they also replicated this feature of the design.

As noted in Smith, 1980, Smith, 1982a, Smith, 1982b, the fact that such markets converge to CE allocations-despite traders having incomplete information about supply and demand conditions-is a challenge for neoclassical theories of competition. ${ }^{2}$ Few, perhaps none, of the critical theoretical conditions for the existence of a CE are satisfied in the double auction markets in Table 1. In these markets there are few traders, each possessing incomplete information, bidding and asking to make (as opposed to take) their own prices. Yet these markets reliably converge to the CE. It is thus all the more surprising that in four early experiments reported by Vernon Smith in Table 1, when traders were actually provided complete information about supply and demand, the double auction no longer reliably converged! In a slightly different institutional environment, Kachelmeier and Shehata (1992) also report weaker price convergence to the CE when traders have complete information. ${ }^{3}$ 
Smith (1980) remarks that in adjusting an experimental trading environment nearer to the conditions that generate a theoretical CE, it is natural to suppose that "market convergence would improve, or at minimum not be worse" in practice (p. 357). Nevertheless, in the sessions highlighted in bold in Table 1, the evidence suggests otherwise. Fig. 2 shows data from Smith (1980). The figure contains two excess supply, "swastika" design sessions with complete and incomplete information. In Fig. 2a, we see that after four trading periods, the two sessions in which traders' values and costs are private information have converged to (or very close to) the CE outcome.

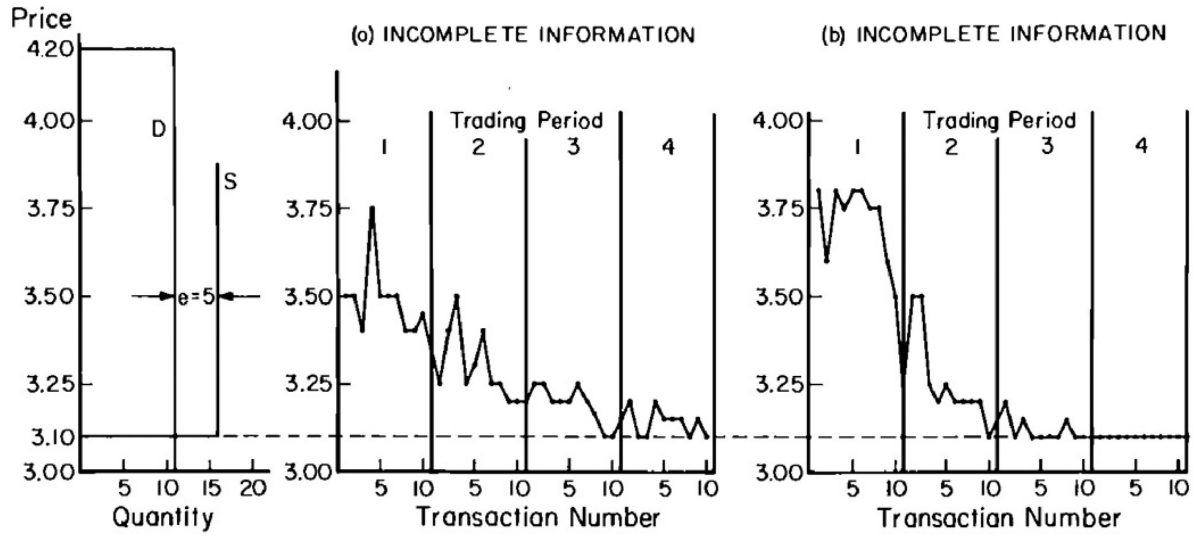

(a) Figure 5a and 5b from Smith (1980) - Incomplete Information

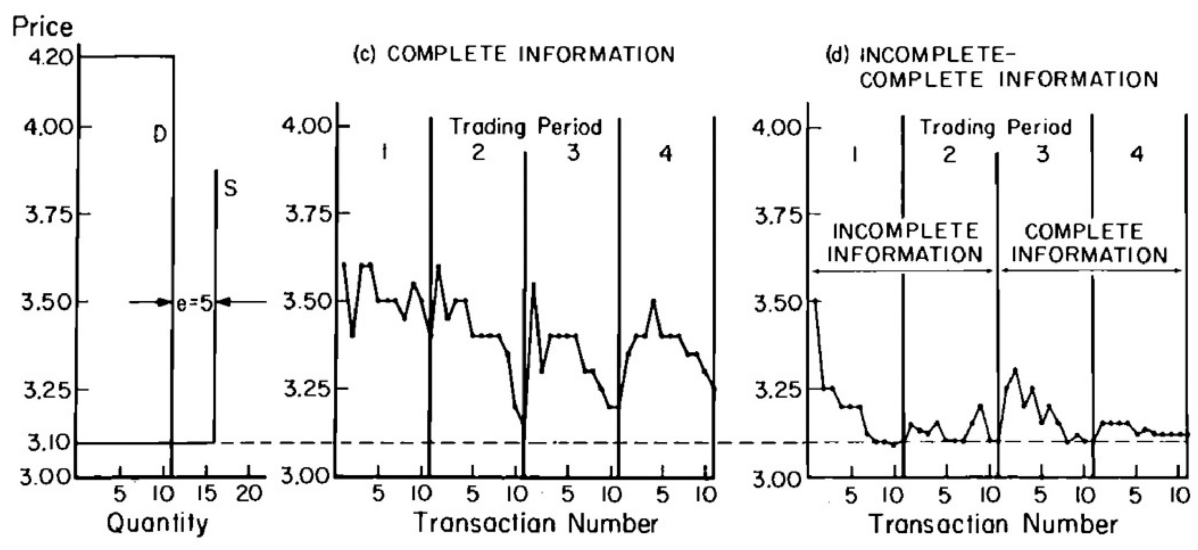

(b) Figure 5c and 5d from Smith (1980) - Complete Information

Fig. 2. Previous complete information experiments, 5 units excess.

However, in Fig. 2b, the first panel reveals little sign of convergence. The second panel, with two periods of incomplete information followed by two periods of complete information, provides limited evidence of (near) price convergence after an initial spike in prices following the introduction of complete information. Fig. 3 shows that this pattern also presents in experiments with an excess supply of 8 rather than 5 units. Smith (1982b) notes that "in this supply and demand design, complete information means that both buyers and sellers are aware of the extreme asymmetry in the gains from exchange at prices near the C.E. Consequently, sellers hold out for higher prices [...] Similarly, buyers 
bid higher or accept higher offers, perhaps because of egalitarian motives or because they do not want to risk failing to make a contract" (p. 946).

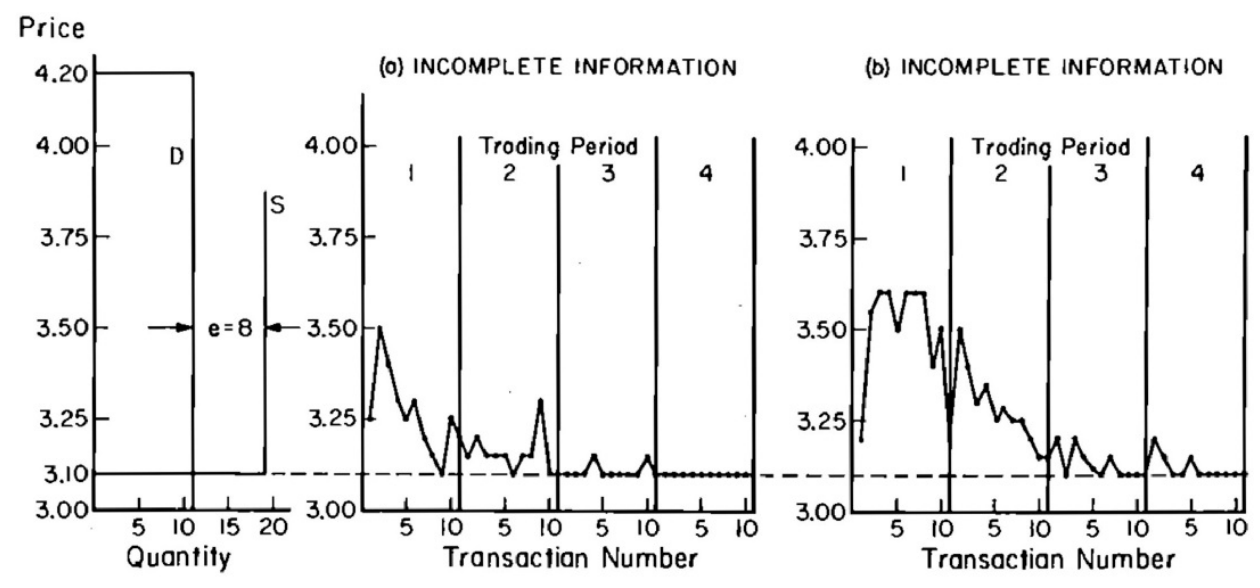

(a) Figure 6a and 6b from Smith (1980) - Incomplete Information

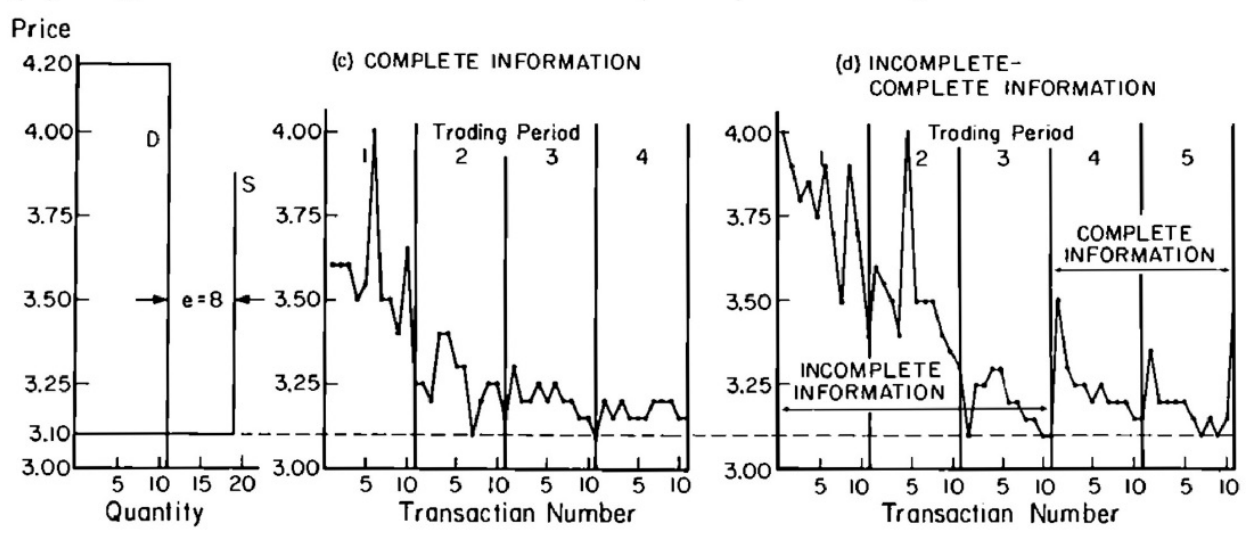

(b) Figure 6c and 6d from Smith (1980) - Complete Information

Fig. 3. Previous complete information experiments, 8 units excess.

The experiments by Kachelmeier and Shehata (1992) support Smith's observations, and together these experiments suggest that providing traders with complete information in the double auction can impede convergence to the CE. On the other hand, while (Smith, 1982b) highlights possible strategic behavior as a source of non-convergence, the market environment studied in all these sessions is not conducive to non-competitive outcomes because such outcomes require coordinated collusive behavior on the part of multiple traders. No single trader has market power, and thus this design may not give non-competitive outcomes their best shot.

Indeed, in one of the few other papers to provide evidence of double auction markets for non-durables that fail to converge to the CE, Holt et al. (1986) introduce supply and demand arrays with asymmetric market power in which a single trader may withhold marginal units to raise the price. A replication by Davis and Williams (1991) confirms these results in double auction markets and shows that similar patterns are observed in a posted-offer market. ${ }^{4}$

In light of the evidence that both complete information and market power may impede convergence to CE prices and allocations in laboratory markets, and since market power is a plausible feature of many non-laboratory markets, it is valuable to further investigate the effects of these market characteristics. In this paper, we provide new tests of the robustness of CE convergence in the double auction to the 
presence of complete information about supply and demand and to the presence of market power. We study the double auction because of its well known equilibrating properties. We design a boundary experiment (a lá Smith, 1982b) in which a small number of traders (4 buyers and 4 sellers), each completely informed about the conditions of supply and demand, trade in a double auction market with a "swastika" supply and demand setup that generates extreme earnings inequity at the CE allocation. We compare our results to previous experiments by Smith and Williams (1990) using similar supply and demand arrays, but wherein traders have incomplete information. We also report treatments that vary whether traders possess market power-meaning that they can potentially withhold units from the market to profitably influence prices. Taken together, our experiments probe the boundaries of the double auction's capacity to generate CE allocations.

We observe fairly robust price convergence to the CE under conditions of complete information, absent market power. Thus, we provide new evidence of the striking equilibrating capacity of the double auction, even when subjects are aware of the extreme inequality in earnings at the CE. However, when traders possess complete information and market power, prices and quantities more readily deviate from the $\mathrm{CE}$. A followup treatment retains market power but provides traders with incomplete information as in the standard double auction environment. This allows us to identify whether it is the joint effect of complete information and market power that causes deviations from the CE or whether market power alone is sufficient to impede convergence. In this treatment, we still observe price and quantity deviations from CE, suggesting that market power (and not complete information) is responsible for the observed failures of convergence. The addition of complete information seems only to alter the division of the exchange surplus.

\section{Experimental design}

Our experiment is designed to answer three questions:

1. Does complete information impede convergence to the competitive equilibrium in a double auction?

2. Does this depend on the presence of market power?

3. What is the interaction between market information and market power?

Given the voluminous literature on the convergence properties of the double auction for non-durables under incomplete information, we do not conduct our own control treatment. Instead, we rely on existing experimental evidence to provide the background against which we test our new design. To this end, we base our own design on six experiments reported in Smith and Williams (1990). These experiments are an especially strong test of market convergence to the $C E$, because they feature a small number of buyers and sellers and extreme earnings inequity in equilibrium, both of which may interfere with CE convergence. ${ }^{5}$

The six experiments in Smith and Williams (1990) are computerized, incomplete information double auctions with a "swastika" supply and demand setup. Four buyers and four sellers (with previous double auction experience) interact for a total of 10 trading periods, broken up into two 5 period "weeks." In half the sessions (Sessions 1, 3, and 5), there is excess demand of 5 units in Week 1, and excess supply of 5 units in Week 2 . In the remaining sessions (Sessions 2, 4, and 6), there is excess supply of 5 units in Week 1, and excess demand of 5 units in Week 2. The per unit exchange surplus is always $\$ 1.10$, with an additional $\$ 0.10$ commission going to both buyer and seller on each transacted unit. 
Fig. 4 presents the Smith and Williams data. In Sessions 1, 3, and 5 , the CE price is shown as the lower dashed line during Week 1 and the higher dashed line in Week 2. In Sessions 2, 4, and 6 the CE price is indicated by the higher dashed line in Week 1 and the lower dashed line in Week 2. The CE market quantity is always 11 units, regardless of period or week.

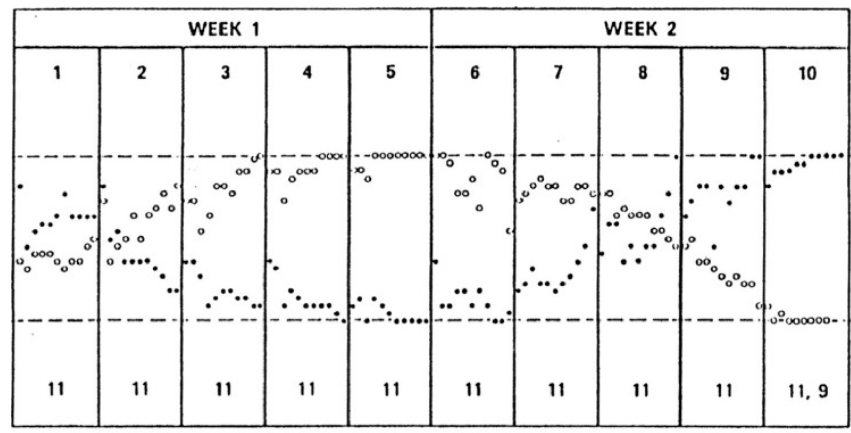

(a) Session 1 (• symbol) and Session 2 (o symbol)

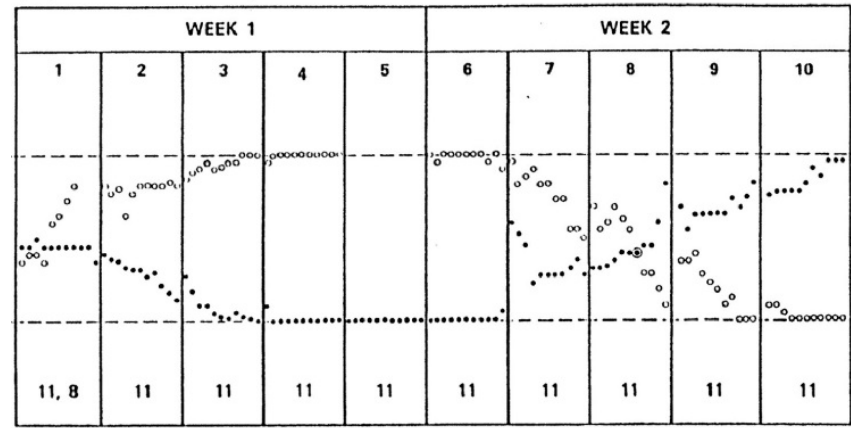

(b) Session $3(\bullet)$ and Session 4 (०)

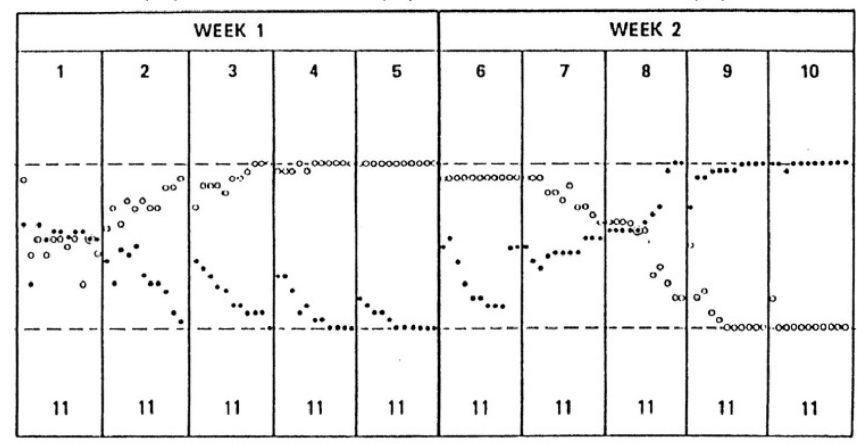

(c) Session $5(\bullet)$ and Session $6(\circ)$

Fig. 4. Experiments from Smith and Williams (1990).

From Fig. 4 we see that transaction prices converged to the equilibrium price in all six sessions by period 5 of Week 1 (period 4 of Week 1 in the case of Session 4). Note also that market efficiency (market quantity divided by 11 units) was $100 \%$ in all but 2 of the 30 trading periods. The Smith and Williams data are striking; despite incomplete information, CE convergence is clearly visible with excess supply (or demand) of 5 units.

Here we note that the Smith and Williams (1990) experiments indicate that five trading periods in a fixed economic environment provide ample time for subjects to learn about their market, and for prices to potentially equilibrate. In our new sessions, four buyers and four sellers interact over five periods in a fixed environment with excess supply (or excess demand) and complete information about supply and demand. We now provide additional details about our experiments. 


\subsection{The institution}

In our experiments, buyers and sellers trade in an oral double auction. Subjects are given record sheets containing their values (or costs) for each trading period (see Appendix C). The experimenter plays the role of auctioneer and accepts oral bids from buyers and oral asks from sellers. ${ }^{6} \mathrm{~A}$ research assistant inputs bids and asks into a computer as they arrive. These bids and asks are displayed in real-time on a projected screen in the center of the room; see Fig. 5. All messages must be sent through the experimenter, and cross-talk is expressly forbidden.

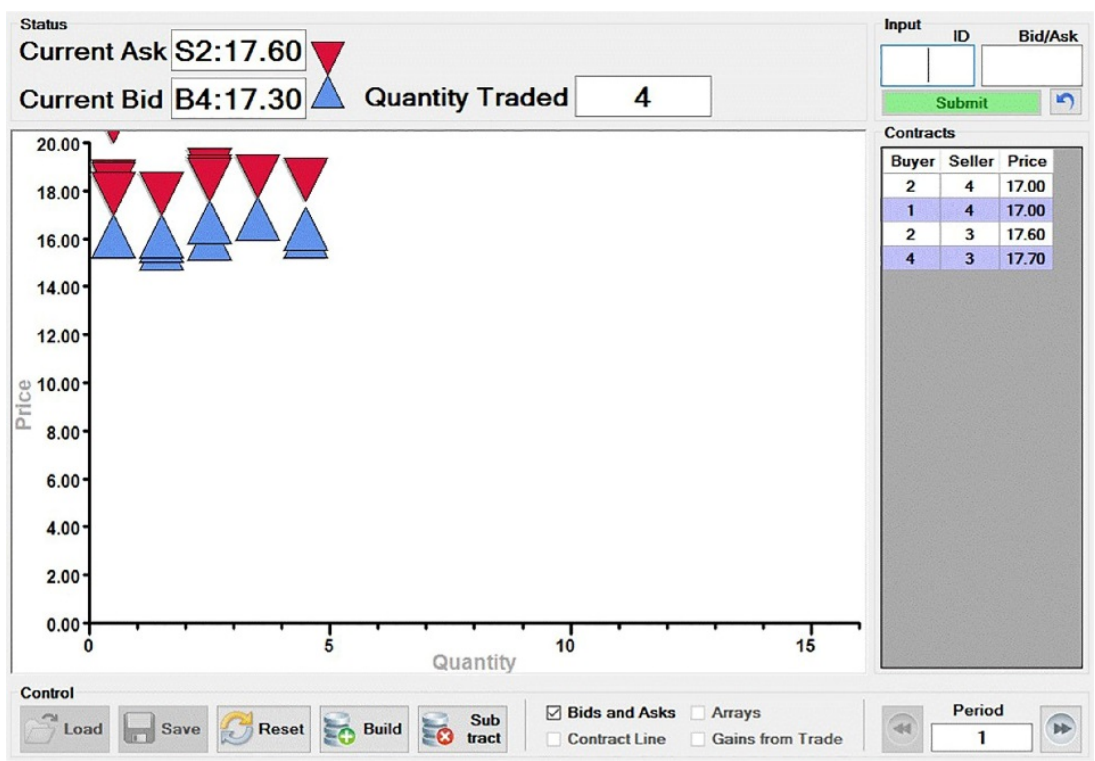

Fig. 5. Screenshot of the projected double auction interface.

A trading period opens with an initial bid from a buyer or an initial ask from a seller. Bids and asks must be multiples of $\$ 0.10$ (to reduce transactions costs). Any subsequent bid or ask must improve upon the current standing bid or ask. Bids and asks continue until one side of the market accepts a price offered by the other side of the market, thus initiating a binding contract. Following a transaction, the order book is cleared, and trading reopens with the solicitation of a new initial bid or ask. The trading period continues until there is no further market activity (i.e. we utilize a "soft close"); this closely follows the 4 markets conducted by Smith noted in Table 1 above. $^{7}$

\subsection{The environment and our treatments}

In our markets, four buyers and four sellers each seek to trade multiple units of a commodity. All buyers value their units at $\$ 17.70$, and all sellers face make-to-order unit costs of $\$ 15.40$. In addition, every trader receives a commission of $\$ 0.25$ per unit traded. We vary aspects of the economic environment to identify the effects of complete information and market power on convergence to the competitive equilibrium.

\subsubsection{Complete information}

Our first two treatments closely follow the environment in Smith and Williams (1990). In our Dx5 (read: "excess demand of 5 units") and Sx5 sessions, the supply and demand arrays induce, respectively, excess demand and excess supply of 5 units. In $D \times 5$ (Sx5) four buyers (sellers) can each trade four units, while three sellers (buyers) each have three units to trade and one seller (buyer) has two units to trade. The primary difference between our design and that of Smith and Williams is that in our markets traders possess complete information about supply and demand. ${ }^{8}$ Thus, our treatments will allow us to 
see whether complete information impedes convergence in markets that are closely comparable to the experimental markets reported in Smith and Williams (1990).

Before discussing our market power treatments, we note that there is no strong theoretical reason to expect differences in CE convergence in a world of excess demand compared to a world of excess supply. Despite this, previous experiments suggest that subjects may be "better at" being buyers. In the double auction literature, buyers tend to earn an outsized share of the gains from trade along the path to convergence (see e.g. Smith and Williams, 1982). Our design examines both excess demand and excess supply markets, so it allows for the possibility that buyers and sellers may differ in the effectiveness with which they attempt to influence prices.

\subsubsection{Market power}

We now discuss two treatments that introduce market power via a subtle change in the underlying supply and demand configuration. Specifically, in our Dx1 and Sx1 sessions, the supply and demand arrays induce an excess demand (supply) of only 1 unit. In $D \times 1$ (Sx1), four buyers (sellers) each still have four units to trade, but now three sellers (buyers) each have four units to trade, while a single seller (buyer) has only three units to trade. In other words, the supply and demand arrays for Dx1 and Sx1 take the arrays from $D \times 5$ and $S \times 5$ and simply increase the quantity supplied by each seller in $D \times 5$ and the quantity demanded by each buyer in $5 \times 5$, by one unit. As we explain below, this change creates incentives for strategic withholding by buyers in $D \times 1$ and by sellers in $S \times 1$.

Holt et al. (1986) define "market power" as the ability of a buyer (seller) to unilaterally, profitably lower (raise) the market price by restricting demand (supply), where no seller (buyer) can profitably respond by counter-withholding. In their environment, there are five buyers and five sellers, and the market does not have a "swastika" supply and demand configuration. Importantly, market power in their design is asymmetric, in that only two of the five buyers (sellers) can profitably affect the market by withholding units. Moreover, counter-withholding is not possible.

In contrast to Holt et al. (1986), in our design, market power is symmetric. All four of our Dx1 buyers (Sx1 sellers) can potentially, profitably withhold units. Moreover, if $D x 1$ buyers (Sx1 sellers) withhold, traders on the other side of the market can potentially, profitably counter-withhold. To see how market power might be exercised, consider Fig. 6.

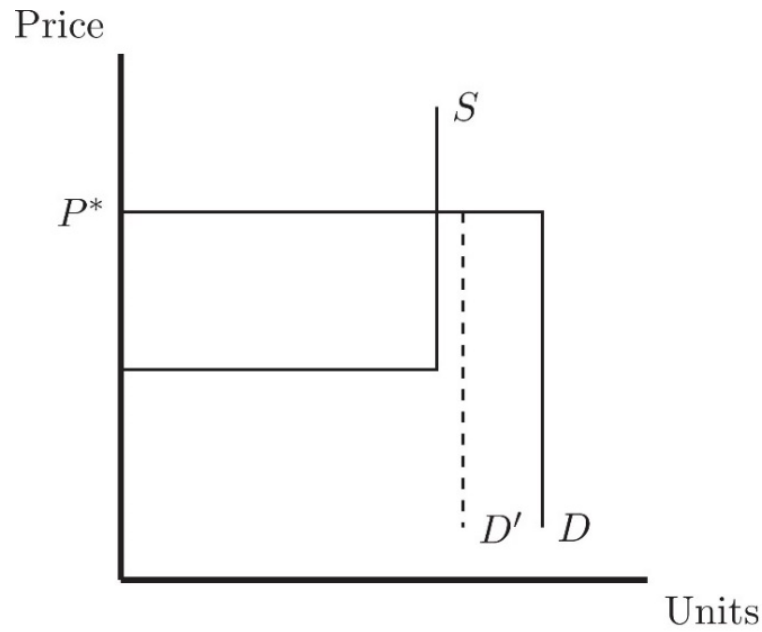

(a) No Market Power

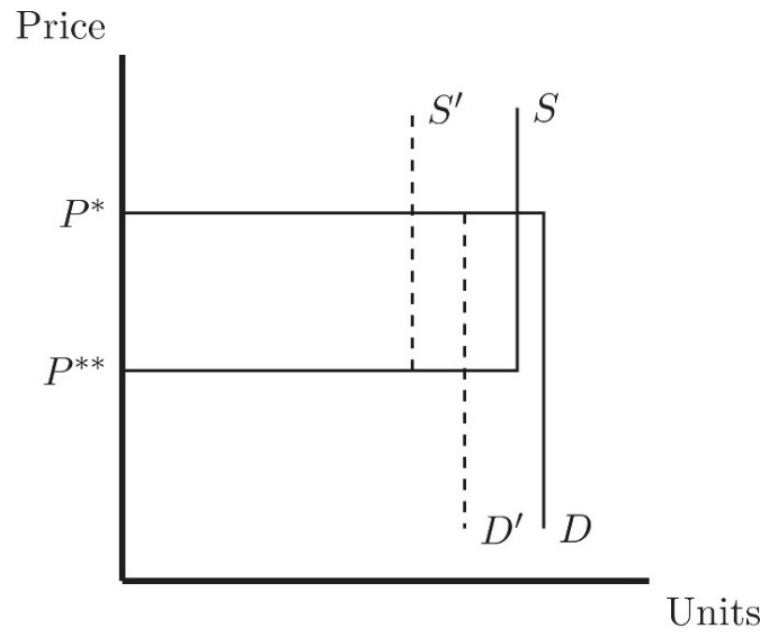

(b) Market Power

Fig. 6. Withholding examples. 
In panel 6 a, which represents the market conditions in $D \times 5$, each buyer has 4 units of demand, but excess demand totals 5 units. Because of this, a single buyer withholding units (and thereby shifting the inverse demand curve from $D$ to $D^{\prime}$ ) is unable to affect the competitive equilibrium. In other words, a buyer cannot profitably lower the market (CE) price by withholding demand; no buyer can exercise market power.

Now consider panel $6 \mathrm{~b}$, which represents the market conditions in $D x 1$. Here a single buyer withholding units is able to influence the CE in the market. With our parameterization, any $D \times 1$ buyer would rather buy two units for a commission-inclusive surplus of $\$ 5.10$, than buy three units or four units for a commission-inclusive surplus of $\$ 0.75$ or $\$ 1.00$. However, if a Dx1 buyer's withholding strategy implies an inverse demand curve of $D^{\prime}$, any seller whose profit is affected by the buyer's actions finds it profitable to counter-withhold-thus shifting the supply curve to $S^{\prime}$ in panel $6 \mathrm{~b}$.

As noted in Holt (1989) (see also Davis and Williams, 1991): "[T]he Nash equilibrium for a single market period, whatever this equilibrium may look like, cannot involve quantity withholding; it is always best to sell inframarginal units at the last instant [...] [Q] uantity reductions in an ODA [oral double auction] setting can only be motivated by dynamic considerations." The key implication is that the Nash Equilibrium of the repeated double auction with market power does not correspond to the CE. Strategic withholding may be profitable over the 5 trading periods of our market power treatments, and any withholding strategy will cause deviations from the CE. We do not attempt to calculate the Nash Equilibrium in mixed strategies (since our main objective is to compare observed outcomes to the $\mathrm{CE}$ ), but the point remains that the subtle change in supply and demand from $x 5$ to $x 1$ provides scope for market power to impede convergence to the CE.

Because we are aware of no previous double auction experiments with "swastika" supply and demand arrays and market power, we also conduct an incomplete information version of $D x 1$ which we refer to as iDx1 (the $i$ denotes incomplete information). In iDx1 all buyers' values and sellers' costs are private information. ${ }^{9}$ This treatment allows us to determine whether any price convergence consequences of the $D \times 1$ and $S \times 1$ treatments are driven by complete information or the joint presence of both complete information and market power.

\subsubsection{Switchover}

Another striking feature of the Smith and Williams (1990) experiments is that, after 5 periods of trading in an excess demand (supply) environment, the authors introduce a subtle change in parameters to create a symmetric excess supply (demand) environment, so that the new equilibrium assigns the entire surplus at the CE to the opposite side of the market as in the first 5 periods. This subtle change consists of changing the quantity demanded or supplied by each trader, but it provides an additional sharp test of CE convergence in the double auction. Such "switchover" sessions provide an answer to the question: "Do prices generated by the double institution quickly adjust to a change in parameters that changes the competitive equilibrium?" In the case of Smith and Williams, the answer is unequivocally yes (see Fig. 4).

We conduct our own Switchover sessions; two sessions with excess demand-to-excess supply (one with an excess of 1 unit; the other with an excess of 5 units), and two sessions with excess supply-to-excess demand (again, one with an excess of 1 unit; the other with an excess of 5 units). We refer to these sessions as $D S \times 1, D S \times 5, S D \times 1$, and $S D \times 5$. 
The switchover is conducted as a surprise restart. At the conclusion of 5 trading periods, new record sheets inducing the new supply and demand are handed out, a brief instruction period provides complete information about the new supply and demand arrays, and trade resumes following the same procedures as before.

Our Switchover sessions allow us to examine the responsiveness of prices to changes in the underlying market configuration. Because previous experiments have shown that prices exhibit a hysteresis effect, that is, they lag in the transition from one equilibrium to another (see e.g. Figs. 1 \& 2 in Smith, 1980), we have reason to believe that "switching over" to a new CE configuration may exaggerate any observed non-convergent tendencies.

\subsection{Procedures}

These experiments were conducted between September 2016 and February 2017 at Simon Fraser University. The sessions took between 60 and 120 minutes depending on the treatment. Subjects received paper copies of the instructions (See Appendix A for the instructions) which were read aloud by the experimenter. During the instruction period, examples were given showing how to compute earnings and how to conduct trade in the market. Subjects were dispersed around the experiment room to prevent cross-talk and were explicitly told not to engage in such talk. After concluding the experiment, subjects completed a brief questionnaire and then were paid privately and dismissed. See Appendix B for a copy of the questionnaire and Table B1 for a summary of responses.

Subjects were recruited online from the general student body. Prior to the study, no subject had experience trading in an incentivized oral double auction market. Subjects received a payment of $\$ 7.00$ for arriving to the session on time. This show-up payment, plus their cumulative earnings from all trading periods, was paid to them in cash at the conclusion of the session. Salient payments ranged from $\$ 1.00$ to $\$ 93.50$. All payments were made in CAD. Table 2 summarizes the experimental design; cf. Table 1 for a comparison to the literature.

Table 2. Summary of sessions.

\begin{tabular}{|c|c|c|c|c|c|c|c|c|c|}
\hline Treatment & Sessions & $\begin{array}{l}\text { Complete } \\
\text { Information }\end{array}$ & $\begin{array}{l}\text { Hand- } \\
\text { run }\end{array}$ & Periods & $\begin{array}{l}\text { Excess } \\
\text { Supply }\end{array}$ & Units & $\begin{array}{l}\text { Buyers \& } \\
\text { sellers }\end{array}$ & Commission & $\begin{array}{l}\text { Closing } \\
\text { Rule }\end{array}$ \\
\hline$D \times 5$ & 3 & Yes & Yes & 5 & No (5) & Mult. & $4 \& 4$ & $\$ 0.25$ & Soft \\
\hline$S \times 5$ & 3 & Yes & Yes & 5 & Yes (5) & Mult. & $4 \& 4$ & $\$ 0.25$ & Soft \\
\hline$D \times 1$ & 3 & Yes & Yes & 5 & No (1) & Mult. & $4 \& 4$ & $\$ 0.25$ & Soft \\
\hline$i D \times 1^{a}$ & 4 & No & Yes & 5 & No (1) & Mult. & $4 \& 4$ & $\$ 0.25$ & Soft \\
\hline Sx1 & 3 & Yes & Yes & 5 & Yes (1) & Mult. & $4 \& 4$ & $\$ 0.25$ & Soft \\
\hline$S D \times 1$ & 1 & Yes & Yes & $5 / 5$ & $\begin{array}{l}\text { Yes/No } \\
\text { (1) }\end{array}$ & Mult. & $4 \& 4$ & $\$ 0.25$ & Soft \\
\hline$D S \times 1$ & 1 & Yes & Yes & $5 / 3$ & $\begin{array}{l}\text { No/Yes } \\
\text { (1) }\end{array}$ & Mult. & $4 \& 4$ & $\$ 0.25$ & Soft \\
\hline SDx5 & 1 & Yes & Yes & $5 / 5$ & $\begin{array}{l}\text { Yes/No } \\
\text { (5) }\end{array}$ & Mult. & $4 \& 4$ & $\$ 0.25$ & Soft \\
\hline$D S \times 5$ & 1 & Yes & Yes & $5 / 5$ & $\begin{array}{l}\text { No/Yes } \\
\text { (5) }\end{array}$ & Mult. & $4 \& 4$ & $\$ 0.25$ & Soft \\
\hline
\end{tabular}

Notes: A slash indicates switchover in excess supply to excess demand. In all cases total available surplus/unit was $\$ 2.30$.

an all but two sessions, the vertical axis in Fig. 5 stretched from $\$ 0-\$ 20$. In the last two iDx1 sessions, the axis stretched from $\$ 0-\$ 30$. 


\section{Results}

To briefly summarize our main results, in this section we report evidence of price convergence to the CE under complete information in the absence of market power. However, with market power, prices persistently deviate from the $\mathrm{CE}$, and efficiency is reduced. Our incomplete information treatment with market power also exhibits non-convergence suggesting that it is market power, and not complete information, driving our results. We also report limited evidence of hysteresis in our switchover sessions without market power, though we observe striking persistence of prices after the switchover with market power. Finally, we observe little evidence of individual behavior consistent with strategic withholding.

\subsection{Price convergence}

Figs. 7 and 8 display the supply and demand arrays (and resulting CE prices) and time series of transaction prices for the $x 5$ (no market power) and $x 1$ (market power) treatments, respectively. While we conducted only 3 sessions of each treatment, we had four additional "switchover" sessions in each of which the first 5 periods were identical to one of our main treatments. We report these first 5 periods as Session 4 in Figs. 7 and 8. For clarity, we display equilibrium prices both ignoring and accounting for the $\$ 0.25$ commission. References to CE prices in what follows will be to the CE price ignoring traders' commissions. The upper panels (a) and (b) show prices from all trading periods in each session, and the lower panels (c) and (d) show only transactions in the final trading period of each session. The latter figures reveal whether prices have converged by the end of each session, after subjects have gained some trading experience. 


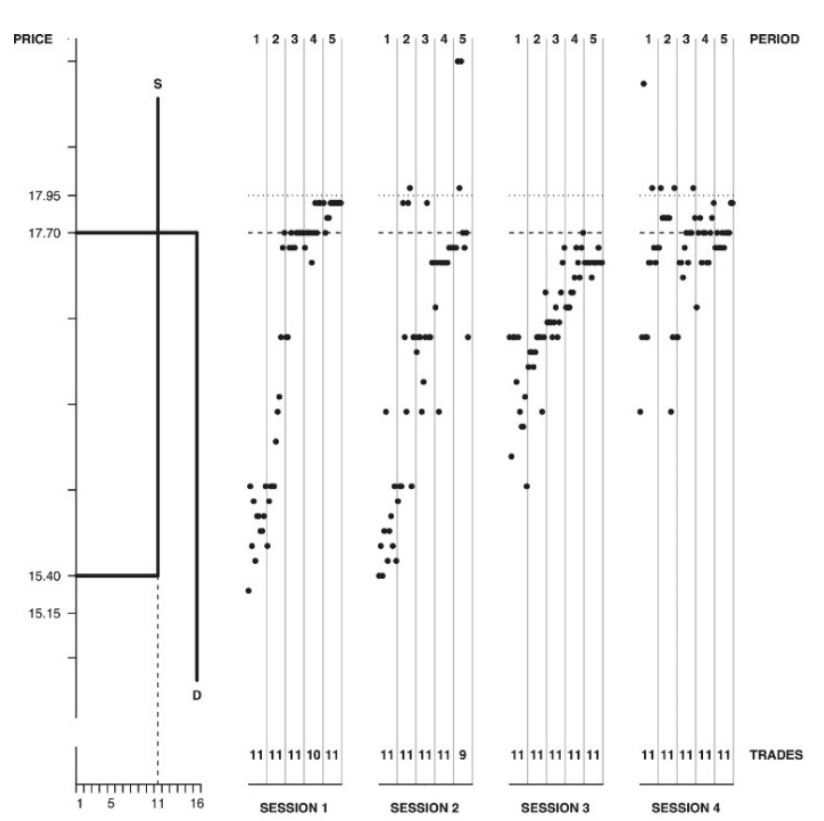

(a) Dx5, All Periods

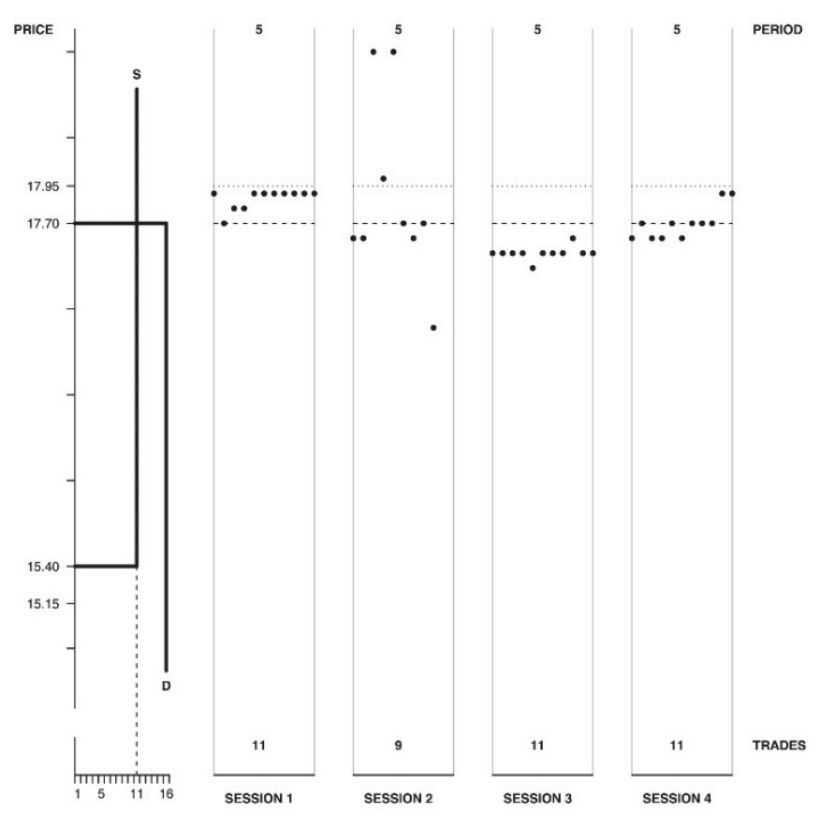

(c) Dx5, Period 5 Only

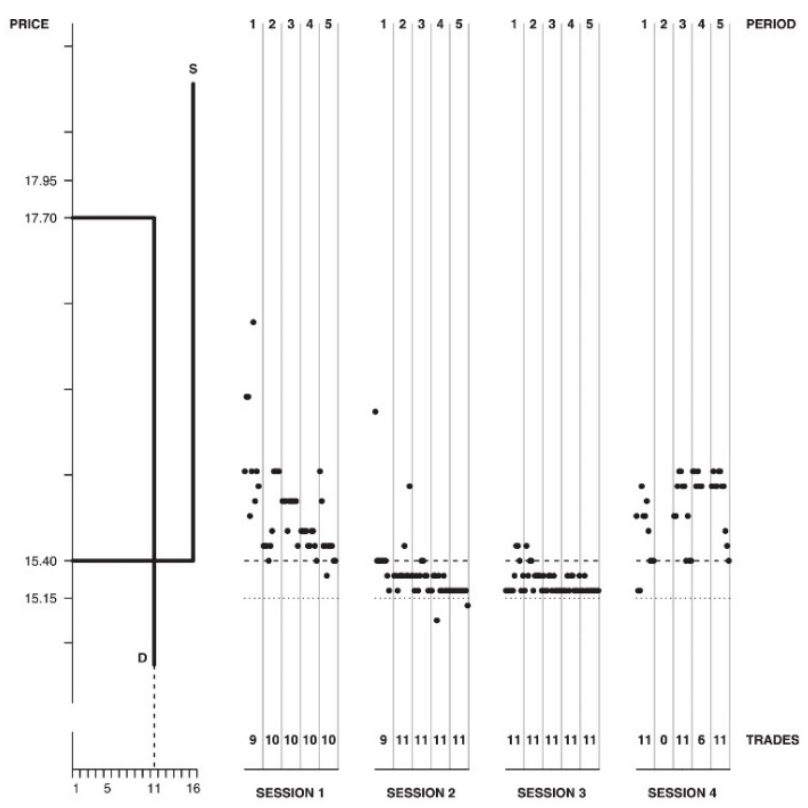

(b) $S x 5$, All Periods

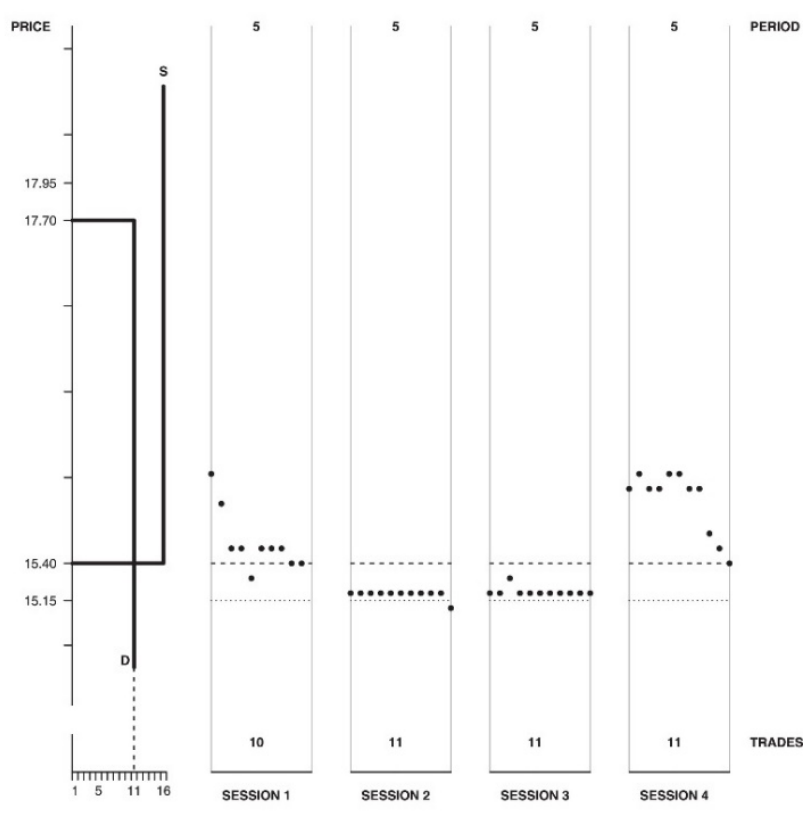

(d) $S x 5$, Period 5 Only

Fig. 7. The $D \times 5$ and $S \times 5$ Sessions.

Note: In Dx5, Session 2, Period 5, prices of $\$ 19.00$ and $\$ 20.00$ are graphed at $\$ 18.85$. 

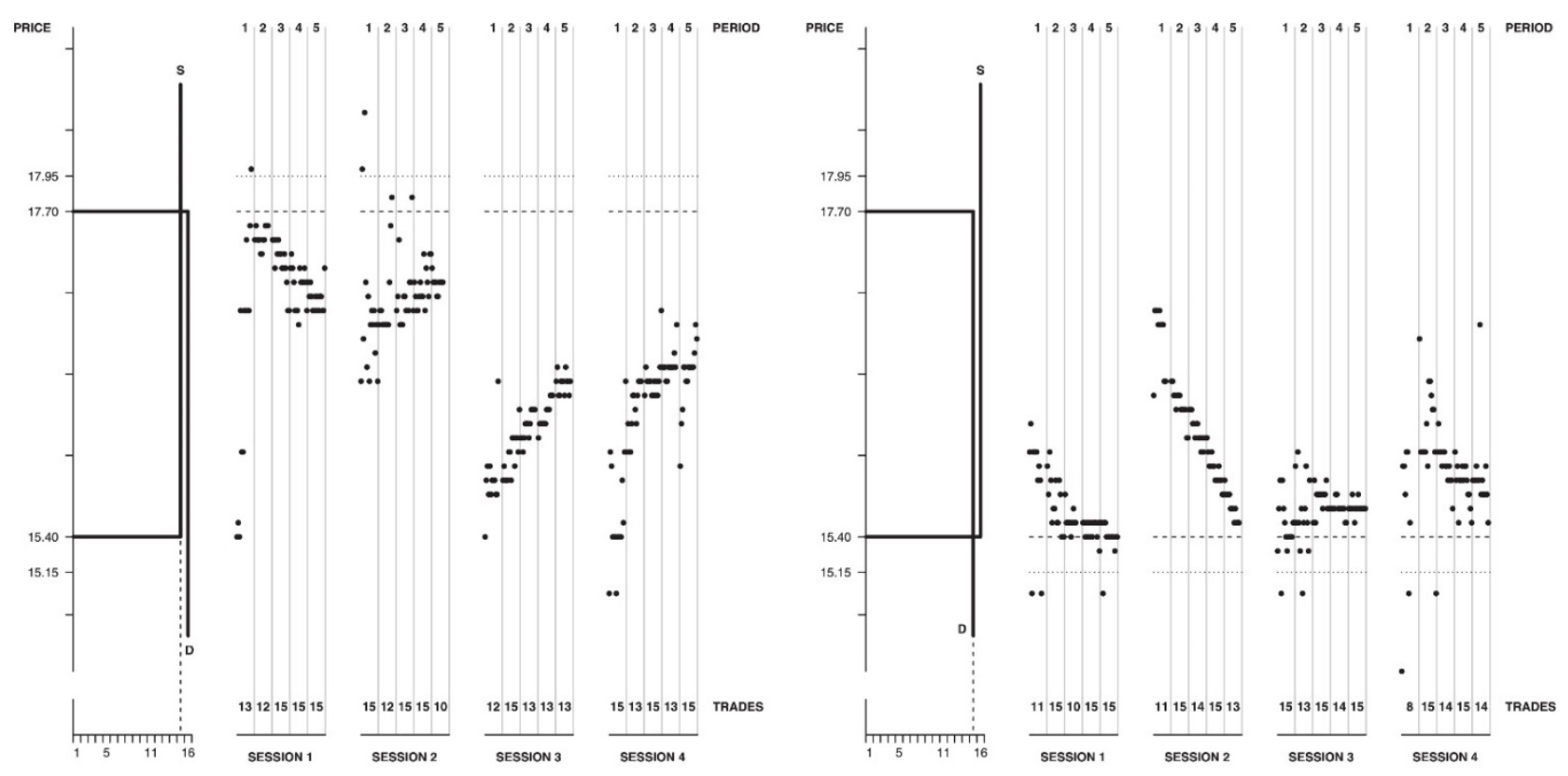

(a) Dx1, All Periods

(b) $S x 1$, All Periods
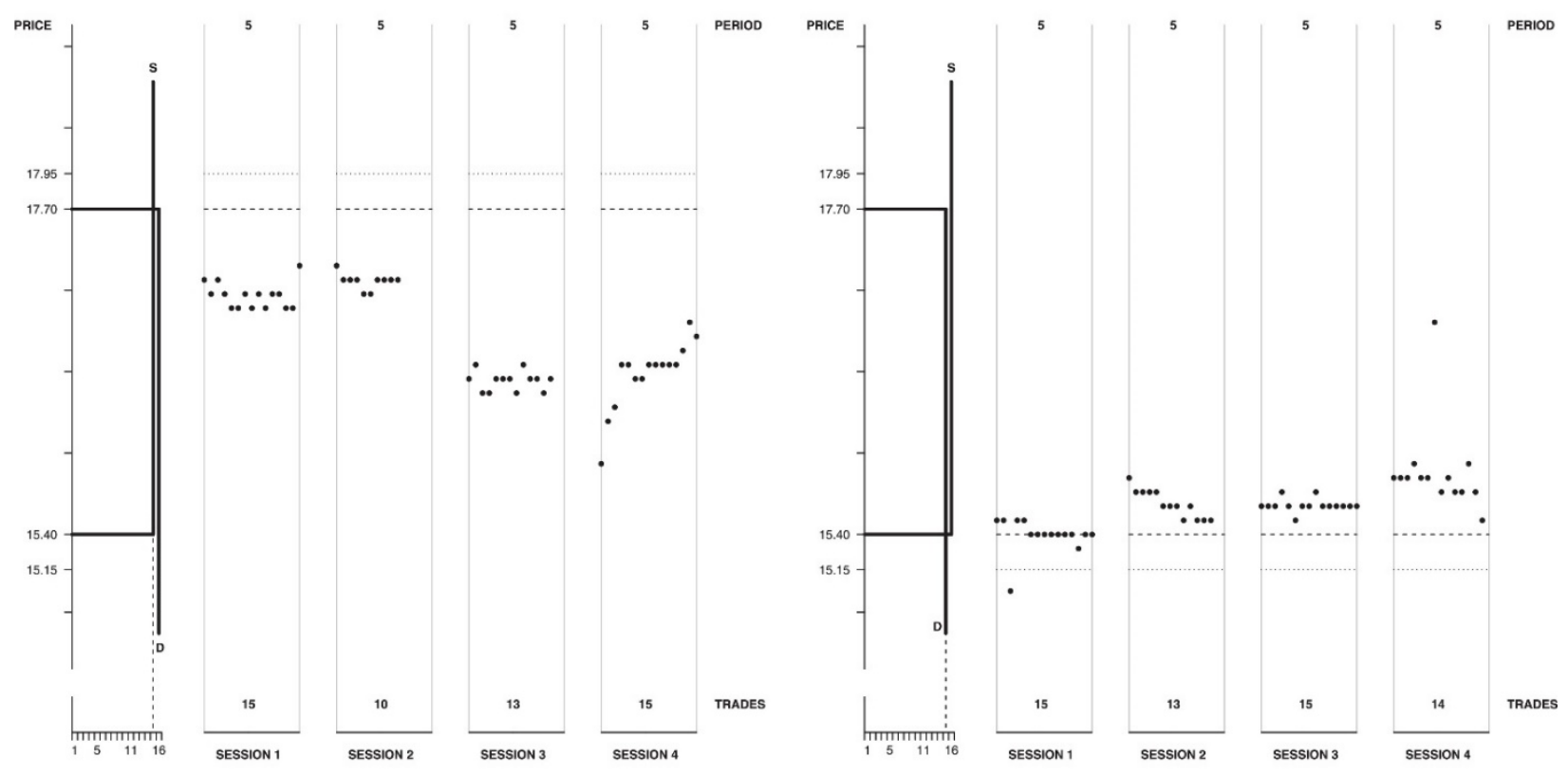

(c) Dx1, Period 5 Only

(d) Sx1, Period 5 Only

Fig. 8. The $D \times 1$ and $S \times 1$ Sessions.

Note: In Sx1, Session 4, Period 1, a price of $\$ 5.00$ is graphed at $\$ 14.45$.

As can be seen in the top two panels of Fig. 7, prices generally converge toward the CE over time, though they appear to do so more quickly in the treatment with excess supply. By the final period of trading, nearly all transaction prices are at or close to the CE price in both $x 5$ treatments. Evidence of price convergence is much weaker in Fig. 8. In fact, panel (a) reveals that only 5 of 274 (1.8\%) Dx 1 transaction prices are at or above the CE price. While prices are closer to the CE in $S \times 1$, only Session 1 has units trade at or below the CE price in period 5.

Table 3 reports summary statistics on prices, quantities, and efficiencies by treatment; the left side of the Table reports averages for all periods and the right side just for period 5 . Consistent with the 
figures, average transaction price is lower (i.e. further from the CE) in the excess demand treatments when buyers have market power than when they do not (by the equivalent of $22 \%$ of total surplus). Similarly, average transaction price is higher, and hence further from the CE, with market power under excess supply (by the equivalent of $11 \%$ of total surplus).

Table 3. Summary statistics by treatment.

\begin{tabular}{|c|c|c|c|c|c|c|c|c|}
\hline \multicolumn{3}{|c|}{ All periods } & \multicolumn{5}{|c|}{ Period 5 only } & \multirow[b]{2}{*}{$\bar{Q} / Q^{*}(\%)$} \\
\hline Treatment & $\bar{P}$ & $\overline{P-P}$ & $\bar{Q}$ & $\bar{Q} / Q^{*}(\mathbf{\%})$ & $\bar{P}$ & $\bar{P}$ & & \\
\hline$D \times 5$ & 17.19 & -0.53 & 10.85 & 98.64 & 17.76 & 0.06 & 10.50 & 95.45 \\
\hline \multirow[t]{2}{*}{$D \times 1$} & 16.67 & -1.03 & 13.70 & 91.33 & 16.80 & -0.90 & 13.25 & 88.33 \\
\hline & -0.51 & & & -7.30 & -0.96 & & & -7.12 \\
\hline $5 \times 5$ & 15.48 & 0.08 & 9.80 & 89.09 & 15.44 & 0.04 & 10.75 & 97.73 \\
\hline \multirow[t]{2}{*}{$S \times 1$} & 15.75 & 0.35 & 13.60 & 90.67 & 15.61 & 0.21 & 14.25 & 95.00 \\
\hline & +0.26 & & & +1.58 & +0.17 & & & -2.73 \\
\hline
\end{tabular}

Notes: $\bar{P}$ is the average transaction price of all units transacted in a treatment. All prices are denominated in CAD. $\bar{Q}$ is the average market quantity in a period, in a treatment.

We employ mixed effects regression analysis of transaction price deviation from the CE to provide statistical support for the foregoing observations on price convergence. More specifically, we estimate the following specification separately for the excess demand and excess supply treatments: ${ }^{10}$

(1)

$$
P_{i j t}-P_{j}^{*}=\beta_{0}+\beta_{1} \text { Unit }_{i j t}+\beta_{2} t_{j}+\beta_{3} \text { MktPower }_{j}+\beta_{4} t_{j} \times \text { MktPower }_{j}+\mu_{j}+v_{0 j t}+v_{1 j t} \text { Unit }_{i j t}+\epsilon_{i j t}
$$

In the specification, $P_{i j t}$ is the price of unit $i$ in period $t$ of session $j . P_{j}^{*}$ is the CE price in session $\mathrm{j} .{ }^{11}$

Unit ${ }_{i j t}$ is the transaction number ( 1 through the number of units sold) in the trading period, divided by the equilibrium number of transactions; this controls for a within-period trend in prices. The variable $t_{j}$ is the trading period $t$ in session $j$, which controls for a trend across trading periods, and $\mathrm{MktPower}_{j}$ is a market power treatment dummy. Also, $\mu_{j}$ denotes the $j$ th session-specific random effect, $v_{0 j t}$ denotes the nested random effect of the $t$ th period within the jth session, and $\epsilon_{i j t}$ is the remaining error. We cluster standard errors at the session level. The regression output from estimating model (1) is reported in Table 4.

Table 4. Regression analysis of price convergence.

\begin{tabular}{|l|l|l|l|l|}
\hline & Dx5 & Dx1 & Sx5 & Sx1 \\
\hline Period 1 & $-1.43^{* * *}$ & $-1.54^{* * *}$ & 0.23 & 0.44 \\
\hline Period 2 & $-1.06^{* * *}$ & $-1.36^{* * *}$ & 0.19 & $0.41^{*}$ \\
\hline Period 3 & $-0.69^{* * *}$ & $-1.19^{* * *}$ & 0.16 & $0.38^{* *}$ \\
\hline Period 4 & $-0.33^{* * *}$ & $-1.01^{* * *}$ & 0.12 & $0.35^{* * *}$ \\
\hline Period 5 & 0.04 & $-0.83^{* * *}$ & 0.08 & $0.32^{* * *}$ \\
\hline
\end{tabular}

Notes: The estimates are $\widehat{\beta_{0}}$ for $D \times 5$ and $S \times 5$ and $\widehat{\beta_{0}}+\widehat{\beta_{3}}$ for $D \times 1$ and $S \times 1$ plus multiples of $\widehat{\beta_{2}}$ and $\widehat{\beta_{4}}$ for each period. Significance stars are from Wald tests of the hypothesis that the relevant coefficients sum to 0 : ${ }^{* * *} p<0.01,{ }^{* *} p<0.05$, $* p<0.1$. 
In Table 4, note that Dx5 prices deviate from the CE initially, but converge over time. Dx5 prices are statistically indistinguishable from the CE by period 5. In the $5 \times 5$ treatment, prices are statistically indistinguishable from the $C E$ in the first period of trading and remain so in all subsequent periods. In $D \times 1$ and $S \times 1$, where the exercise of market power is possible, prices are statistically different from the CE in all periods save for Period 1 of $S \times 1$. Finally, we see evidence that prices converge faster under excess supply than excess demand in our $x 5$ treatments and that prices tend to be further from the CE under excess demand than excess supply in our $x 1$ treatments.

\section{Finding 1}

With complete information, prices converge to the CE when buyers (sellers) do not have market power.

\section{Finding 2}

When buyers (or sellers) have market power, prices fail to converge to the CE price under complete information.

\section{Finding 3}

With or without market power, prices are slower to converge or further from the CE when there is excess demand than when there is excess supply.

Finding 1 suggests that Smith's conjecture in our epigraph and the results of the four complete information sessions reported in Smith (1980) are not entirely robust. In our experiments, we find solid evidence of price convergence under complete information, so long as buyers do not possess market power. ${ }^{12}$ Finding 2 extends the findings of Holt et al. (1986) and Davis and Williams (1990) to markets in which buyers and sellers possess complete information. Finding 3 is consistent with the observation in Smith and Williams (1982) that subjects are "better at" being buyers, in that buyers tend to earn a relatively larger share of the surplus than sellers in double auction markets. This seems to carry over to environments with market power, as buyers in Dx1 drives prices further from the CE than do sellers in Sx1.

\subsection{Efficiency}

In previous research, one consequence of the robust equilibrating tendency of the continuous double auction is the institution's ready ability to generate efficient resource allocations. We have just seen that CE prices emerged in our $x 5$ treatments, but not in our $x 1$ treatments with market power. As noted above, the failure of our market power sessions to yield CE prices may, or may not, affect allocative efficiency; there exists a continuum of mutually acceptable prices that simply alter the distribution of the gains from exchange without impacting efficiency. We now examine whether the introduction of market power reduces allocative efficiency.

Table 3 shows the average number of units transacted per trading period, by treatment. First, as shown in Figs. 7 and 8 subjects transacted fewer than the efficient number of units in a sizable share of all trading periods. Specifically, fewer than $Q^{*}$ units were sold in $50 \%$ of trading periods in which market power was present (10/20 in both $D \times 1$ and $S \times 1)$ versus only $25 \%$ of periods in which traders possessed no market power (8/20 periods in $S \times 5$ and 2/20 in Dx5). Thus, with both excess supply and excess demand, the presence of market power reduced the number of periods in which the efficient quantity was traded. 
We measure efficiency as the number of units transacted divided by the CE quantity. Since the available exchange surplus is constant for each unit in our design, this is equivalent to the popular (Plott and Smith, 1978) measure of efficiency: observed total surplus over possible total surplus. Note that this means that our design maximizes the efficiency loss from withholding a unit at the CE. ${ }^{13}$

Efficiency is $99 \%$ in the Dx5 treatment, suggesting that complete information does not necessarily interfere with market efficiency in the absence of market power. However, efficiency hovers around $90 \%$ in the other three treatments. ${ }^{14}$ To test for treatment differences in efficiency, we estimate the following mixed effects specification separately for the excess demand and excess supply treatments (analogous to the analysis above):

$$
Q_{j t} / Q_{j}^{*}=\beta_{0}+\beta_{1} t_{j}+\beta_{2} \text { MktPower }_{j}+\beta_{3} t_{j} \times \text { MktPower }_{j}+\mu_{0 j}+\mu_{1 j} t_{j}+\epsilon_{j t}
$$

$Q_{j t} / Q_{j}^{*}$ is efficiency in period t of session $\mathrm{j}$. The variable tj is the trading period $\mathrm{t}$ in session $\mathrm{j}$, which controls for a trend across trading periods, and MktPowerj is a market power treatment dummy. Also, $\mu 0 \mathrm{j}$ denotes the jth session-specific random effect, $\mu 1 \mathrm{j}$ denotes the nested random effect of the th period within the jth session, and $\in$ jt is the remaining error. We cluster standard errors at the session level.

Table 5 contains results from estimating Eq. (2). The analysis reveals that efficiency differs significantly from $100 \%$ in all treatments but $D \times 5 .{ }^{15}$ This effect is mitigated over market periods in both excess supply treatments, but is not mitigated in $D x 1$. The reported estimates for $D x 1$ are not in error; the coefficient estimate on $t$ and that on $t \times$ MktPower are very similar but of opposite sign.

Table 5. Regression analysis of efficiency.

\begin{tabular}{|l|l|l|l|l|}
\hline & Dx5 & Dx1 & Sx5 & Sx1 \\
\hline Period 1 & 1.01 & $0.91^{* * *}$ & $0.84^{* *}$ & $0.82^{* * *}$ \\
\hline Period 2 & 1.00 & $0.91^{* * *}$ & $0.86^{* *}$ & $0.86^{* * *}$ \\
\hline Period 3 & $0.99^{*}$ & $0.91^{* * *}$ & $0.89^{*}$ & $0.91^{* * *}$ \\
\hline Period 4 & 0.98 & $0.91^{* * *}$ & 0.92 & $0.95^{* * *}$ \\
\hline Period 5 & 0.96 & $0.91^{*}$ & 0.95 & 0.99 \\
\hline
\end{tabular}

Notes: The estimates reported are $\widehat{\beta_{0}}$ for Dx5 and Sx5 and $\widehat{\beta_{0}}+\widehat{\beta_{2}}$ for Dx1 and Sx1 plus multiples of $\widehat{\beta_{1}}$ and $\widehat{\beta_{3}}$ for each period. Significance stars are from Wald tests of the hypothesis that the relevant coefficients sum to $1: * * * p<0.01,{ }^{* *} p$ $<0.05, * p<0.1$.

The individual coefficient estimate on MktPower $\left(\hat{\beta}_{2}\right)$ in model $(2)$ is for the excess demand treatments, and this estimate is significantly different from zero $(p=0.03)$ The point estimate is -0.03 for the excess supply treatments, which is not significantly different from zero $(p=0.80)$. Our regressions results imply that in the excess supply treatments, efficiency is initially significantly below $100 \%$ in both $S \times 5$ and $S \times 1$. Efficiency increases over time in both treatments, but more quickly in $S \times 5$ than in $S \times 1$.

\section{Finding 4}

Market power reduces efficiency in the excess demand environment under complete information. With or without market power, efficiency becomes indistinguishable from $100 \%$ over time in the excess 
supply environment with complete information. However, efficiency is slower to reach $100 \%$ with market power.

At this point, it is unclear whether market power and complete information together hamper price convergence and allocative efficiency, or whether market power alone is sufficient to produce these results. To address this question, we now examine our $i D \times 1$ sessions which are identical to our $D \times 1$ sessions, but provide traders with incomplete as opposed to complete information. That is, values and costs are private information under $i D x 1$.

\subsection{Incomplete information and market power}

Are the deviations from the CE price and quantity in our $x 1$ treatments driven by market power per se, or by the joint presence of market power and complete information? (Holt et al., 1986) and Davis and Williams (1991) find evidence of price deviations from the CE in double auctions with incomplete information and asymmetric market power. This suggests that market power may be the primary driver of the findings we report above.

To test this conjecture, we need data from incomplete information markets with symmetric market power. To the best of our knowledge, no one has conducted such sessions before. Thus, we report four sessions of an incomplete information version of our $D \times 1$ treatment, which we call iDx1. As noted above, the only difference between this treatment and $D x 1$ is that subjects are not informed about other traders' values or costs prior to trading.

Fig. 9 displays the supply and demand arrays (and resulting CE price) and time series of transaction prices for iDx1. Panel (a) shows prices from all trading periods in each session, and panel (b) shows only prices in the final trading period of each session. Thus, panel (b) highlights whether prices have converged to the CE by the end of each session.

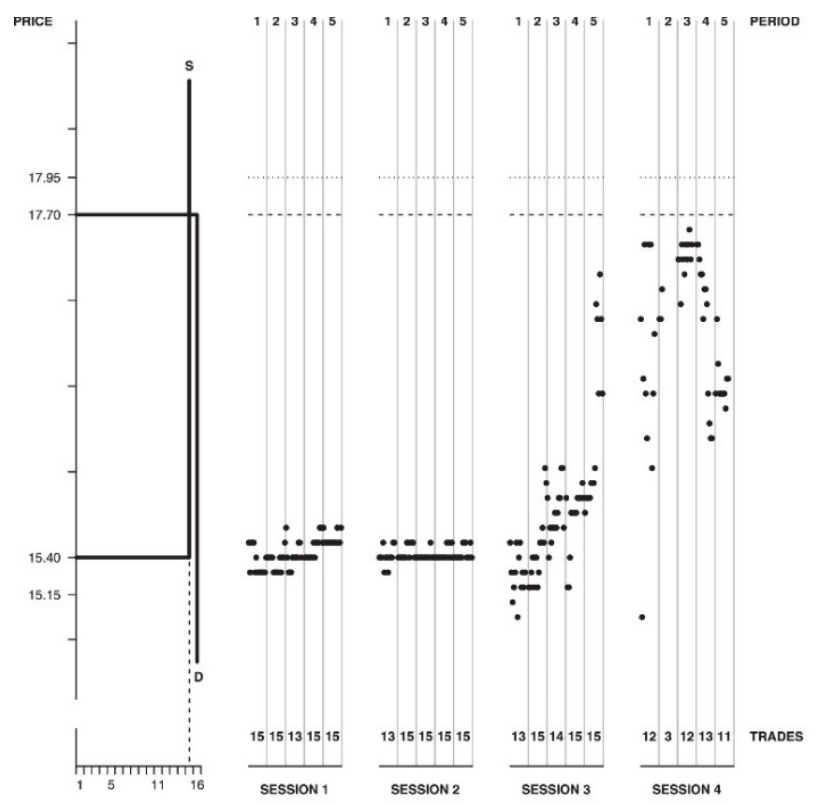

(a) All Periods

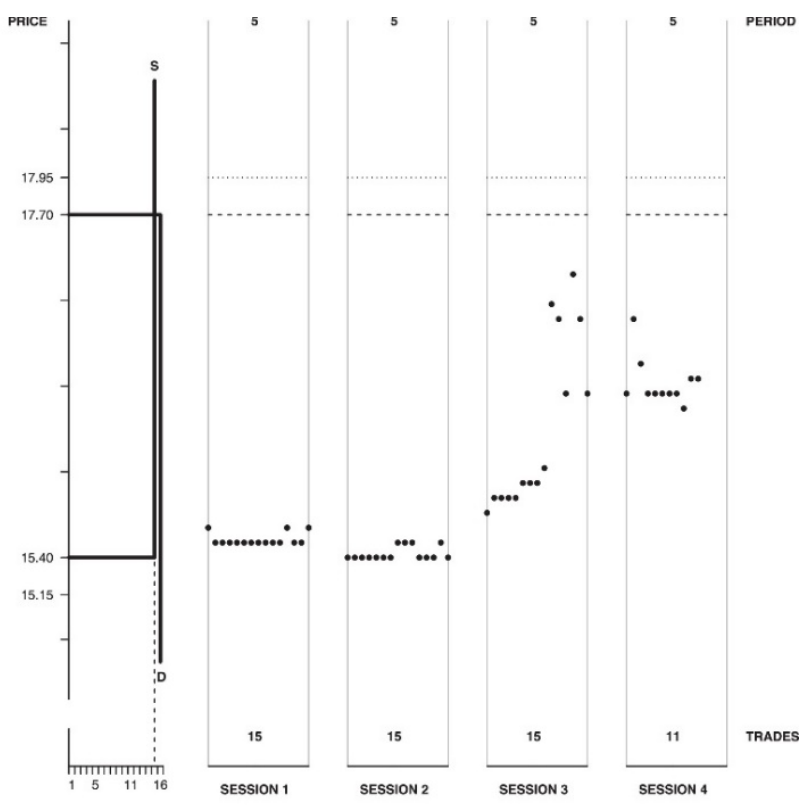

(b) Period 5 Only

Fig. 9. The iDx1 sessions. 
As in the $D x 1$ treatment, we see very little evidence of price convergence in the $i D x 1$ treatment. None of the 269 transactions occurs at a price at or above the CE. In fact, in two of the sessions prices converge rapidly to suppliers' costs; that is, buyers so effectively exploit their market power that prices are as if the environment had excess supply rather than excess demand! ${ }^{16}$

Table 6 displays summary statistics from both the $D \times 1$ and $i D x 1$ treatments to facilitate comparison; as before we show data for all periods and for period 5 only. The average transaction price in the iDx 1 sessions is $\$ 0.89$ lower (i.e. further from the CE) than in the Dx1 sessions. Table 6 also shows average efficiency, which was similar in both treatments. The summary data suggest that: (1) it is market power and not the combination of market power and complete information that hampers price convergence to the CE, (2) information may affect the magnitude of the price deviation which (3) may affect the distribution of realized surplus.

Table 6. Summary statistics by treatment.

\begin{tabular}{|c|c|c|c|c|c|c|c|c|}
\hline \multicolumn{4}{|c|}{ All periods } & \multicolumn{4}{|c|}{ Period 5 only } & \\
\hline Treatment & $\bar{P}$ & $\overline{P-}$ & $\bar{Q}$ & $\bar{Q} / Q^{*}(\mathbf{\%})$ & $\bar{P}$ & $\bar{P}$ & & \\
\hline$D \times 1$ & 16.67 & -1.03 & 13.70 & 91.33 & 16.80 & -0.90 & 13.25 & 88.33 \\
\hline$i D \times 1$ & 15.78 & -1.92 & 13.45 & 89.67 & 15.90 & -1.80 & 14.00 & 93.33 \\
\hline & -0.89 & & -0.25 & -1.67 & -0.90 & & +0.75 & +5.00 \\
\hline
\end{tabular}

Notes: $\bar{P}$ is the average transaction price of all units transacted in a treatment. All prices are denominated in CAD. $\bar{Q}$ is the average market quantity in a period, in a treatment.

We estimate analogs to specifications (1) and (2), but with MktPower $j$ replaced by a dummy for the incomplete information treatment (Incomplete ${ }_{j}$ ), and using only $D x 1$ and $i D x 1$ data in our estimating sample. For price convergence, we find that $i D x 1$ is not significantly different from $D \times 1(p=0.536)$. The treatment effect on $P_{i j t}-P_{j}^{*}$ is significant and negative in each period (all $p$-values $<0.000$ ). With respect to allocative efficiency, $i D x 1$ is again not significantly different from $D \times 1$ ( $p=0.487)$. Finally, the model's estimate of efficiency in each trading period is significantly less than $100 \%$ in periods $1-3$, but not in periods 4 and 5 .

\section{Finding 5}

Price deviations from the CE are driven primarily by market power, rather than complete information. Complete information may affect the magnitude of price deviations and thus alter the distribution of surplus.

Having established that market power affects price convergence and allocative efficiency, we next ask how prices adjust when we change the environment within-session from one of excess demand to one of excess supply and vice versa.

\subsection{The switchover sessions}

We next report the findings from our four Switchover sessions. Given the small number of sessions (DSx5, SDx5, DSx1, and SDx1), these observations should be taken as merely suggestive. However, they do reinforce the evidence reported above on the role of market power in price deviations from the CE.

Fig. 10 displays time series of the CE price and observed transaction prices for each Switchover session. After the 5th trading period of each Switchover session, we conduct a surprise restart, and we increase demand (supply) and decrease supply (demand). This changes the CE price, and flips the equilibrium 
distribution of surplus. In three of the Switchover sessions, trade continued for another 5 periods; unfortunately, the lengthy bidding process in the first 5 periods of $D S x 1$ meant that there was only time for 3 additional periods of trade.

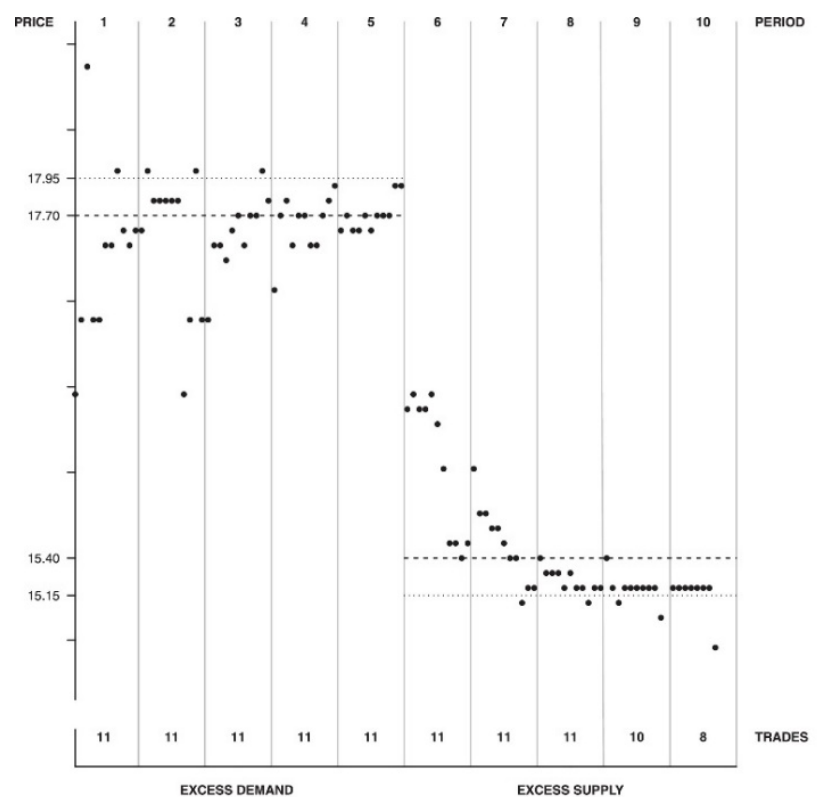

(a) DSx5 Session

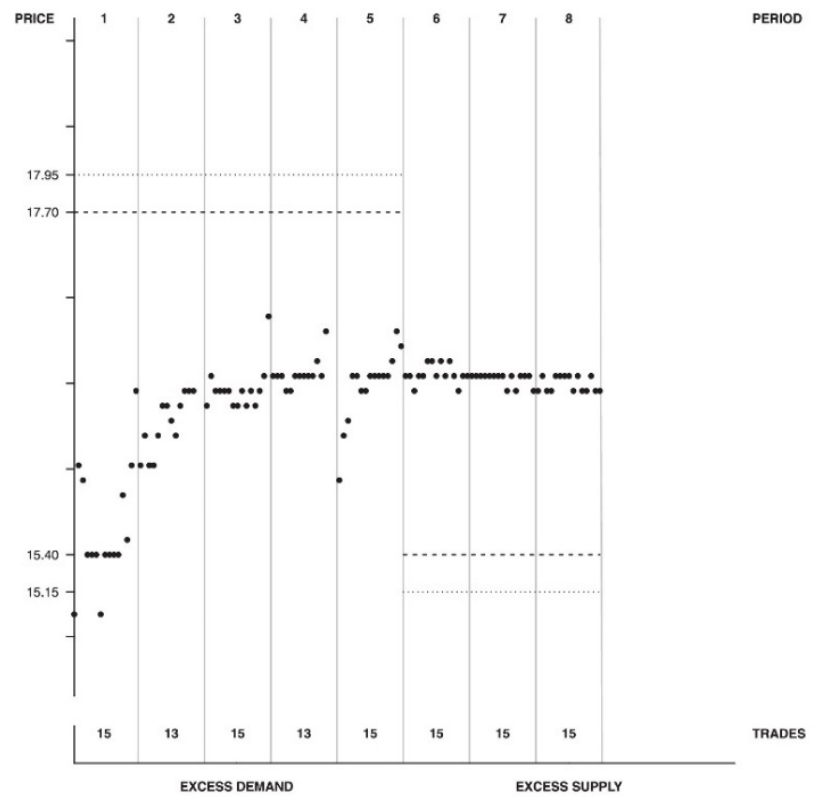

(c) DSx1 Session

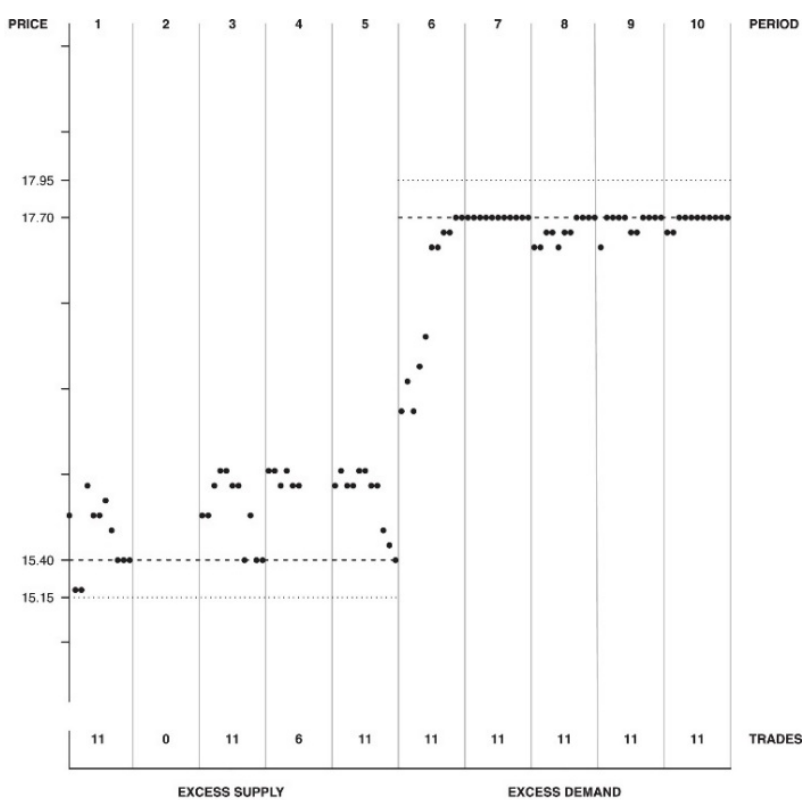

(b) SDx5 Session

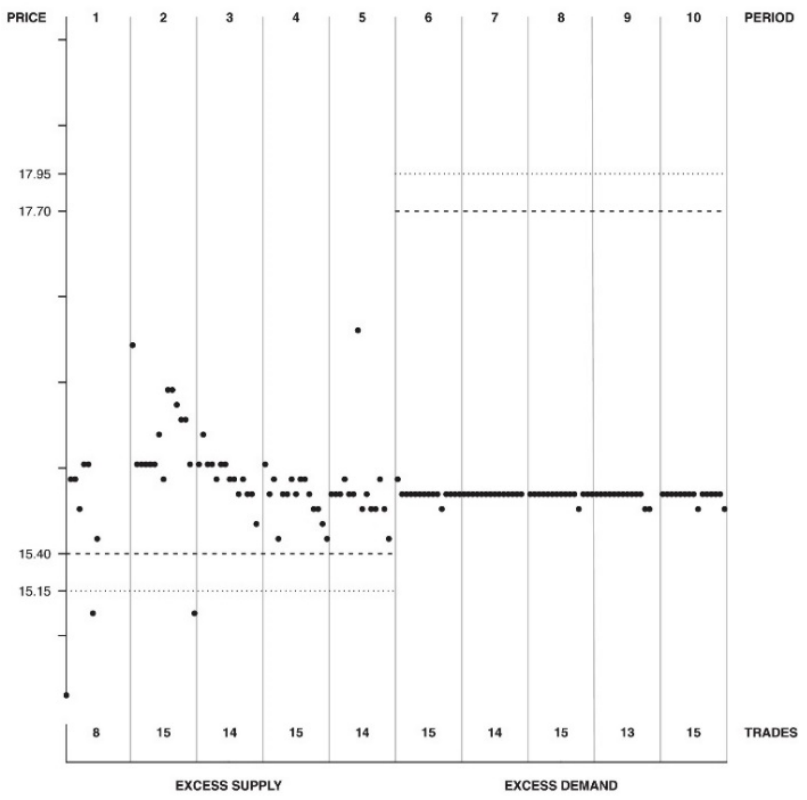

(d) SDx1 Session

Fig. 10. The Switchover Sessions.

Note: In SDx1, Period 1, a price of $\$ 5.00$ is graphed at $\$ 14.45$.

As shown in Fig. 10, both sessions without market power (DSx5 and SDx5) rapidly converge to the new equilibrium price after the switchover. This is consistent with the evidence in Smith and Williams (1990) from incomplete information markets and suggests that the presence of complete information is not sufficient to impede convergence. However, in the two sessions with market power (DSx1 and SDx1), we observe striking hysteresis. Post-switchover transaction prices persist at levels 
very close to those observed in the final transactions of period 5. It is as if "bargaining" in the double auction with market power has generated agreement upon a (roughly) fixed distribution of the surplus from each transaction. ${ }^{17}$ In the two sessions with market power, efficiency is nearly as high postswitchover as in the Dx5 treatment where efficiency is approximately 99\%, which means that the relatively equitable split of the exchange surplus comes at very little cost to efficiency in these sessions.

\section{Finding 6}

As inSmith and Williams (1990), after a switch from excess supply to excess demand (or vice versa), prices rapidly converge to the new CE in our two sessions without market power. With market power, prices hardly change and average prices remain similar to those observed before the switchover.

To reiterate, our experiments highlight the robustness of the continuous double auction in achieving CE allocations of non-durable goods in the absence of market power. This is true even in a complete information environment where, in the competitive equilibrium, the surplus is captured entirely by one side of the market. Moreover, in our limited sample of Switchover sessions, in the absence of market power, we observe rapid convergence to the new CE when values and costs are changed. The renowned power of the double auction begins to falter only in the presence of market power. In the next section we attempt to unpack how exactly market power influences behavior and how changes in observed behavior can be traced to changes in market prices and efficiency.

\subsection{The mechanics of market power}

We begin our detailed examination of market power with summary statistics on bids and asks, by treatment. Two intuitive conjectures about the behavior of subjects attempting to exploit market power suggest themselves: in an environment of excess demand (supply), we may see bids (asks) that are further from the equilibrium price on average, and we may see relatively less market activity per unit transacted by buyers (sellers) as they attempt to withhold units. In Table 7, note that the average bid price was $\$ 1.60$ lower as we move from $D \times 5$ to $D \times 1$, but that the average ask was no lower in $S \times 5$ than $S \times 1$-in fact, $S \times 5$ asks were slightly higher by $\$ 0.08$. Relative to $D \times 5, D \times 1$ sellers had asks that were $\$ 0.43$ lower on average. Curiously, $S \times 1$ buyers lowered their bids by $\$ 0.86$ on average relative to $S \times 5$. Both bids and asks were lower in $i D \times 1$ relative to $D \times 1$.

Table 7. Summary Statistics by Treatment

\begin{tabular}{|c|c|c|c|c|c|c|}
\hline Treatment & Mean bid (\$) & Mean ask (\$) & & Mean bids (\#) & Mean asks (\#) & \\
\hline$D \times 5$ & 16.70 & 17.73 & -1.04 & 3.80 & 2.34 & 1.46 \\
\hline \multirow[t]{2}{*}{$D \times 1$} & 15.09 & 17.30 & -2.21 & 5.18 & 4.51 & 0.66 \\
\hline & -1.60 & -0.43 & & 1.38 & 2.18 & \\
\hline$S \times 5$ & 15.07 & 16.23 & -1.16 & 3.10 & 3.85 & -0.75 \\
\hline \multirow[t]{2}{*}{$S \times 1$} & 14.21 & 16.15 & -1.95 & 2.83 & 3.47 & -0.63 \\
\hline & -0.86 & -0.08 & & -0.27 & -0.39 & \\
\hline$D \times 1$ & 15.09 & 17.30 & -2.21 & 5.18 & 4.51 & 0.66 \\
\hline \multirow[t]{2}{*}{ iDx1 } & 14.14 & 16.48 & -2.33 & 3.50 & 3.89 & -0.39 \\
\hline & -0.95 & -0.83 & & -1.68 & -0.63 & \\
\hline
\end{tabular}

Notes: Mean Bid (Ask) is the average bid (ask) for each unit transacted, averaged over units transacted in a treatment. All prices are denominated in CAD. Mean Bids (Asks) is the average number of bids (asks) on each unit transacted, averaged over units transacted in a treatment.

There were consistently more bids than asks in the complete information excess demand sessions and consistently more asks than bids in the excess supply sessions. ${ }^{18}$ The total number of bids and asks was 
higher in $D \times 1$ than in $D \times 5$, but was essentially the same in both $S \times 1$ and $S \times 5 .{ }^{19}$ Overall, the summary statistics are not particularly penetrating for investigating the mechanics of market power, so we now turn to an examination of individual withholding behavior.

\subsubsection{Individual withholding}

If some buyers (or sellers) engaged in systematic withholding, we would expect them to have traded fewer units overall than their counterparts who did not withhold. In this section, we focus on the side of the market with excess capacity because those subjects earn very little at the CE and may thus wish to manipulate the market. In the excess demand treatments there are 16 units that buyers would like to purchase in a period, and in the excess supply treatments there are 16 units that sellers would like to sell. Given the limited capacity on the other side of the market, not all buyers and sellers will transact all of their units at the CE. In this subsection, we ask: Did some subjects consistently buy (or sell) fewer than the expected number of units at the CE?

In a given period, a buyer in an excess demand treatment or a seller in an excess supply treatment is expected to trade $\frac{Q^{*}}{4}$ units on average at the CE $(2.75$ in the $x 5$ treatments and 3.75 in the $x 1$

treatments), so over the entire 5 market periods of our experiment, we expect them to trade $\frac{5 Q^{*}}{4}$ units. In practice, subjects cannot trade fractional units, and some subjects trade all of their units while others trade fewer units. By simulating a sequence of trades in each market, we can construct a reference distribution for the number of units traded by each subject over the course of the 5 trading periods.

To generate a reference distribution showing the expected number of units bought or sold in the CE for a given buyer (or seller), we simulate 5,000 repetitions of each experimental treatment. For each market period, we simulate a sequence of trades under a random priority assumption, such that at any point in the sequence of trades, all remaining units of demand (or supply) are equally likely to be exchanged in the subsequent transaction. This is equivalent to sampling without replacement from the demand (or supply) schedule until the equilibrium number of units has traded. We repeat this exercise five times to simulate a session of our experiment and then count the number of units traded by each buyer (or seller) to construct a simulated distribution for the expected total number of units bought (or sold) over all 5 periods of each treatment.

We compare this simulated distribution to the empirical distribution from our experiments. For each buyer in the excess demand treatments and for each seller in the excess supply treatments, we calculate the total number of units they actually bought or sold over all 5 trading periods. These empirical distributions are based on 16 observations per treatment ( 4 subjects times 4 sessions). A histogram of the simulated distribution is shown in Fig. 11 for each treatment with the empirical distribution superposed. 


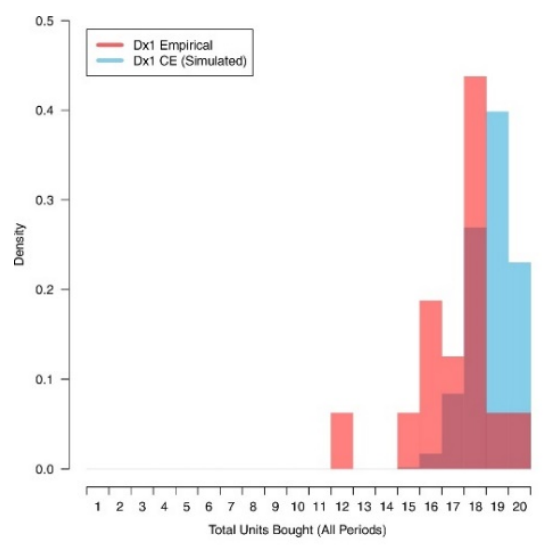

(a) $D x 1$

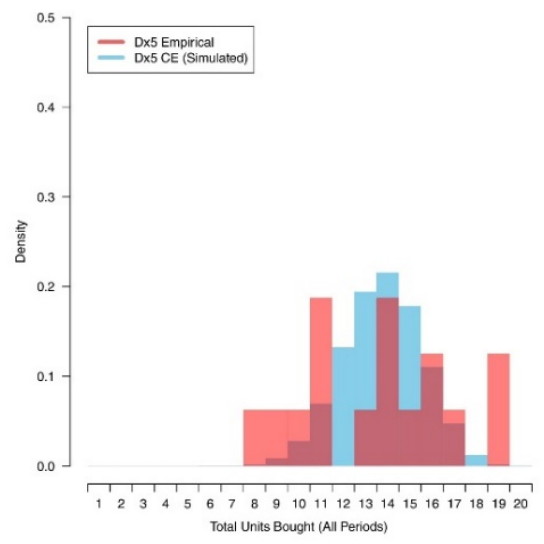

(d) $D x 5$

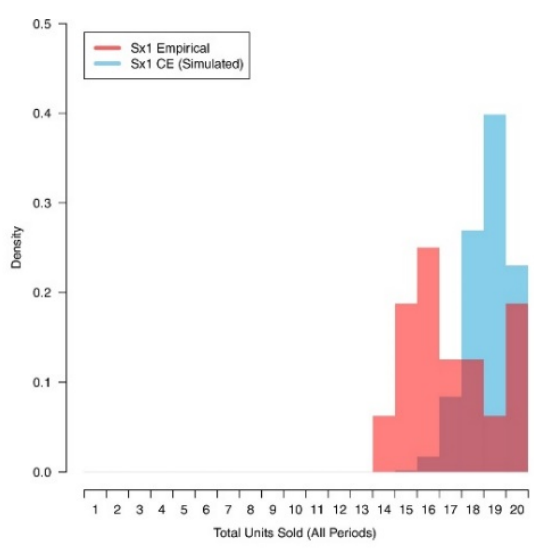

(b) $S x 1$

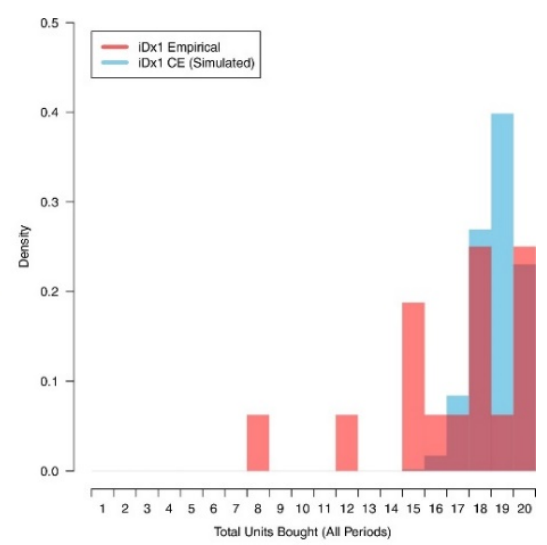

(c) $i D x 1$

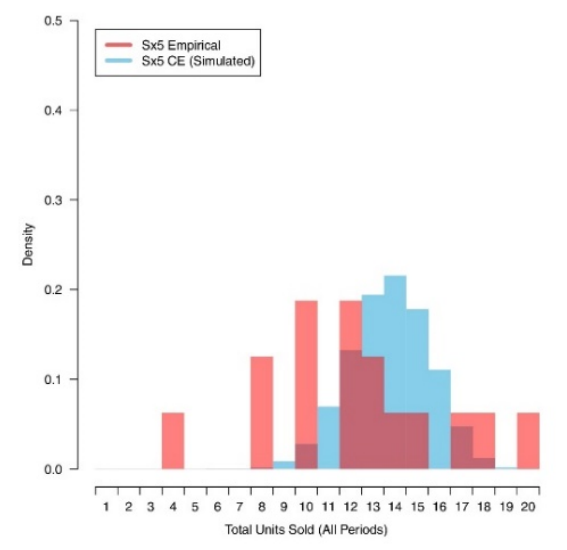

(e) $S x 5$

Fig. 11. Histograms of total units transacted.

The figure reiterates our earlier observation that market efficiency was less than $100 \%$ in all three of our market power treatments because the densities of the empirical distributions lie to the left of the densities of the simulated distributions. We also see considerably more variance in the empirical distributions than in the simulated distributions. There are a few outlying individuals who traded far fewer units than expected in the $\mathrm{CE}$, which is at least consistent with the possibility that some subjects systematically withheld.

Given that we see subjects who traded far fewer units than expected at the CE in our market power sessions, it is natural to ask whether these subjects effectively moved prices away from the CE to their benefit. Pooling over the market power treatments $(S \times 1, D \times 1, i D \times 1)$, we observe no significant correlation between efficiency and the mean absolute difference between observed prices and the $C E$ price in a period $(r=0.16, p$-value $=0.22, N=60)$.

Moreover, there is not much evidence that the most avid withholders impacted prices to their benefit. In Session 3 of $D x 1$, which contains the outlier shown in panel (a) of Fig. 11, prices were slightly further from equilibrium than the $D x 1$ average. However, in Session 3 of $S x 1$, which contained the seller who traded the fewest units overall (shown in panel (b)), average prices are instead closer to the CE than the treatment average. Moreover, in Session 4 of iDx1, which contains the two substantial withholders shown in panel (c) of Fig. 11, prices were actually higher (i.e. closer to the CE) than in all the other sessions of the same treatment. This suggests that to the extent that subjects withhold units, they are not more effective than non-withholders in driving prices away from the CE. 


\section{Finding 7}

In the presence of market power, we observe withholding, and some subjects trade far fewer units than expected at the CE. However, these subjects do not appear to have been any more effective than other subjects at driving prices away from the CE.

\subsubsection{Transaction order}

Suppose that a $D \times 1$ buyer wishes to engage in strategic withholding. This buyer needs to convey an intention to withhold to the other side of the market, but this may be difficult when bidding in a thick market. For example, if this buyer makes a particularly low bid to signal intent to withhold, the bid may be ignored as other non-withholding buyers transact their units. However, if the buyer waits until others have sold most of their units, his threat to withhold becomes more transparent. Similar behavior might be observed if a buyer simply seeks to maximize his bargaining power within a trading period. For instance, suppose a buyer in Dx1 waits to bid until all 12 units of supply that are demanded by other buyers have already been sold. This buyer will establish monopsony power over the final 3 units of supply.

Note that if one or a few subjects wait to buy until later in the period, we will observe a non-random transaction order. Thus, we conclude our examination of the mechanics of market power by asking whether the order of transactions was random in our data.

Consider the following vector, representing the transaction order in a period: $[4,1,4,2, \ldots, 3,2]$. The ith element of this vector tells us who bought the ith unit transacted in period 1 of Session 1 of $D \times 1.13$ units were transacted in this period; Buyer 2 bought two units (the 4th and the 13th units traded). Imagine that these transactions happened in a different order: $[4,1,4,3, \cdots, 2,2]$. We have turned Buyer 2's earliest transaction into a transaction by Buyer 3, and Buyer 3's latest transaction into a transaction by Buyer 2. In the second transaction ordering, Buyer 2's average position is 12.5 compared to 8.5 in the original. The second vector may be consistent with Buyer 2 strategically waiting until the end of the period to buy, as described above.

To determine whether observed transactions were consistent with random ordering, we again employ simulation. For each treatment, market, and session we calculate the empirical average buyer and seller positions in the transaction order (e.g. buyer 2's average position was 8.5 in the example discussed above). Then, again for each treatment, market, and session, we randomly shuffle the empirical transaction order vector 1000 times. We calculate the mean and standard deviation of buyer and seller positions across all 1,000 randomly reshuffled transaction orders.

We then subtract the empirical average position from the simulated average position and check to see if this difference is larger than 1, 2, or 3 standard deviations of the simulated average position in the transaction vector. Table 8 presents the results of this exercise. We see very little evidence of nonrandom ordering overall; less than $5 \%$ of observed transaction orders are more than 2 standard deviations $(2 \sigma)$ from the mean. Note that all 9 of the possibly non-random transaction orders were observed in the three market power treatments. However, in 6 out of the 9 cases, the market was $100 \%$ efficient (i.e. no units were withheld). This leaves 3 market periods (less than 1\%) in which we observe possibly non-random transaction order and less than $100 \%$ market efficiency.

\section{Finding 8}

We see little evidence of market power in the form of non-random transaction order. 
Table 8. Transaction order simulations.

Number of empirical average positions $>X \sigma$ from the simulated mean

\begin{tabular}{|c|c|c|c|c|c|}
\hline Treatment & Session & $1 \sigma$ & $2 \sigma$ & $3 \sigma$ & Observations \\
\hline \multirow[t]{5}{*}{$D \times 1$} & 1 & 5 & 3 & 0 & 20 \\
\hline & 2 & 3 & 1 & 0 & 19 \\
\hline & 3 & 2 & 1 & 0 & 20 \\
\hline & 4 & 4 & 0 & 0 & 20 \\
\hline & & $14(18 \%)$ & $5(6 \%)$ & $0(0 \%)$ & 79 \\
\hline \multirow[t]{5}{*}{ Dx5 } & 1 & 3 & 0 & 0 & 19 \\
\hline & 2 & 7 & 0 & 0 & 20 \\
\hline & 3 & 5 & 0 & 0 & 19 \\
\hline & 4 & 1 & 0 & 0 & 20 \\
\hline & & $16(21 \%)$ & $0(0 \%)$ & $0(0 \%)$ & 78 \\
\hline \multirow[t]{5}{*}{$S \times 1$} & 1 & 2 & 0 & 0 & 20 \\
\hline & 2 & 6 & 1 & 0 & 20 \\
\hline & 3 & 3 & 1 & 0 & 20 \\
\hline & 4 & 4 & 1 & 0 & 20 \\
\hline & & $15(19 \%)$ & $3(4 \%)$ & $0(0 \%)$ & 80 \\
\hline \multirow[t]{5}{*}{$S \times 5$} & 1 & 2 & 0 & 0 & 20 \\
\hline & 2 & 5 & 0 & 0 & 19 \\
\hline & 3 & 3 & 0 & 0 & 20 \\
\hline & 4 & 2 & 0 & 0 & 14 \\
\hline & & $12(16 \%)$ & $0(0 \%)$ & $0(0 \%)$ & 73 \\
\hline \multirow[t]{5}{*}{$i D \times 1$} & 1 & 2 & 0 & 0 & 20 \\
\hline & 2 & 5 & 1 & 0 & 20 \\
\hline & 3 & 1 & 0 & 0 & 20 \\
\hline & 4 & 5 & 0 & 0 & 18 \\
\hline & & $13(17 \%)$ & $1(1 \%)$ & $0(0 \%)$ & 78 \\
\hline
\end{tabular}

Notes: Observations are at the subject-period level. Percentages are column sums divided by the number of observations. When there are fewer than 80 observations for a treatment it is because a subject bought or sold zero units in a period. Note that 4 of the 7 missing subject-period observations from Sx5 are from period 2 of Session 4 in which no units were traded.

\section{Conclusion}

We explore the boundaries of the double auction trading institution for non-durable goods. Smith (1980) reports non-convergence to the competitive equilibrium in double auctions with complete information and a "swastika" supply and demand environment in which all surplus goes to one side of the market in equilibrium. We test the robustness of Smith's conjecture that complete information impedes CE convergence in eight new, structurally similar markets, and we are unable to reproduce this result. After 5 trading periods, market prices are statistically indistinguishable from the CE.

In the aforementioned markets, it is impossible for a single trader to impact prices by withholding capacity; that is, no traders have market power. To provide an even more stringent test of CE convergence in the double auction, we also report eight markets in which we introduce symmetric market power via a subtle shift in supply (or demand). In these markets, prices consistently deviate from the $\mathrm{CE}$, and allocations are consistently less than $100 \%$ efficient. This suggests that introducing both market power and complete information may hamper CE convergence in the double auction. 
Four additional markets conducted with incomplete information and market power indicate that the effect is primarily driven by market power per se and not by complete information.

As Smith (1982b) notes, "Whenever a theory or an empirical regularity has received replicable support from several independent experimental or other empirical studies, and is thereby established as a behavioral law with some claim to generality, it is natural to ask whether one can design experiments that will test for those extreme or boundary conditions under which the law fails" (p. 942). In this tradition, our experiments both bolster previous claims about the striking power of the double auction to generate competitive outcomes and highlight boundary conditions under which the institution falters.

\section{Appendix A. Experiment instructions}

Below we include the full instructions for one of our treatments with complete information. Text in italics was removed for the incomplete information treatment, and information about the number of units available to buyers/sellers was varied according to the treatment condition. All other features of the instructions were unchanged across treatments, including text that was emphasized in bold.

\section{Preliminaries}

Thank you for participating in today's experiment. Your earnings will depend on your own decisions and the decisions of other participants. Your earnings, including your $\$ 7.00$ show-up fee, will be paid to you privately, in cash, at the end of the experiment. Please remain quiet and do not communicate with other participants.

You and the other participants in the experiment have been given either a buyer or a seller record sheet. In addition, you have been given an ID card identifying you as either a buyer or a seller. For example, Buyer 1 has an ID card marked B1, and Seller 1 has an ID card marked S1.

\section{Objective}

The experiment is composed of periods in which you will buy and sell units of a fictional good. In each period, the buyers' task is to purchase a unit (or units) from a seller (or sellers). Likewise, the sellers' task is to sell a unit (or units) to a buyer (or buyers). Record sheets contain information about buyers' values and sellers' costs for units of the good.

Buyers, think of yourselves as agents working on behalf of the experimenter. Your value (values) represents how much money the experimenter will pay you for a unit if you are able to purchase a unit during a period. You will earn the difference between your value for a unit and the price at which you purchase that unit in a period plus a $\mathbf{\$} \mathbf{0 . 2 5}$ commission per unit purchased. You only receive money for units you actually buy, and there is no penalty if you fail to buy a unit.

Sellers, think of yourselves as producers of the fictional good. Your cost for a unit represents the maketo-order cost you would incur were you to produce that unit. You will earn the difference between the price at which you sell a unit in a period and your cost of producing that unit plus a $\$ 0.25$ commission per unit sold. You only incur costs for units you actually sell, and there is no penalty if you fail to sell a unit.

Buyers may buy, and sellers may sell, multiple units, but everyone must buy or sell units in the order they are listed on their record sheet. Also, buyers and sellers can only buy or sell the units for Period 1 in Period 1 (and for Period 2 in Period 2, and so on). Once a buyer has purchased their $1^{\text {st }}$ unit, they can 
try to buy their $2^{\text {nd }}$ unit at a price that may or may not be the same as that of their $1^{\text {st }}$ unit. A seller must sell their $1^{\text {st }}$ unit before they can try to sell their $2^{\text {nd }}$ unit for a price that may or may not be the same as what they sold their $1^{\text {st }}$ unit for.

Buyers can only buy, and sellers can only sell, one unit at a time. In a moment, we will explain how trades take place (and where prices come from), but first, please take a look at the sample record sheet on the screen.

\section{Accounting}

The first record sheet is for a hypothetical buyer, and the second record sheet is for a hypothetical seller. When a buyer pays a price to a seller, both participants write the price on their record sheet. The buyer writes the price in the Price Paid column; the seller writes the price in the Price Received column.

A buyer's profit on a unit is calculated as:

$$
\text { Buyer"sProfit }=\text { Value }- \text { PricePaid }+\$ 0.25 \text { Commission }
$$

Here is an example to illustrate how a buyer's profit is calculated in the experiment: If Buyer $1^{\prime}$ s $1^{\text {st }}$ unit has a value of $\$ 10.20$, and Buyer 1 buys their first unit at a price of $\$ 7.00$, then Buyer 1 earns $\$ 10.20$ minus $\$ 7.00$ plus $\$ 0.25$, or $\$ 3.45$.

A seller's profit on a unit is calculated as

$$
\text { Seller"sProfit }=\text { PriceReceived }- \text { Cost }+\$ 0.25 \text { Commission }
$$

Now consider the same trade from the seller's point of view: If Seller $1^{\prime}$ s $1^{\text {st }}$ unit has a cost of $\$ 3.90$, and Seller 1 sells their first unit at a price of $\$ 7.00$, then Seller 1 earns $\$ 7.00$ minus $\$ 3.90$ plus $\$ 0.25$, or $\$ 3.35$.

Notice that a buyer's profit can be negative if the price that they pay is greater than their value for the unit, and a seller's profit can be negative if the price they receive is less than their cost for the unit!

Remember, buyers do not receive their value for a unit until they purchase the unit, and sellers do not incur their cost for a unit until they sell the unit. Thus, buyers only receive values, and sellers only bear costs, when trades take place.

\section{Buying \& selling}

Buyers submit Bids and sellers submit Asks by raising their ID card and, when acknowledged by the proctor, saying a price out loud. Please do not shout out your Bid or Ask without being called on. The proctor will make an effort to call on buyers and sellers in the order in which they raise their ID cards.

Each new bid must be higher than the current bid. In other words, if a previous buyer bid $\$ 5.00$ then any new bid must be greater than $\$ 5.00$.

Each new ask must be lower than the current ask. If a previous seller asked $\$ 9.00$ then any new ask must be less than $\$ 9.00$.

All bids and asks must be in $\$ \mathbf{0 . 1 0}$ increments. For example, if the current bid is $\$ 5.00$, a new bid must be $\$ 5.10$ or higher. Similarly, if the current ask is $\$ 9.00$, a new ask must be $\$ 8.90$ or lower. 
A bid or ask is only valid if it is recognized by the proctor. The proctor will recognize each bid or ask by repeating it. For example, if Buyer 1 raises their ID card, the proctor will say "Buyer 1?" If Buyer 1 then responds and says "\$5.30," the proctor will say, "Buyer 1 bids $\$ 5.30$." This bid will be recorded on the screen as an upside-down carrot. If Seller 1 raises their ID card, the proctor will say "Seller 1?" If Seller 1 then responds and says "\$8.40," the proctor will say, "Seller 1 asks $\$ 8.40$." This ask will be recorded on the screen as a carrot.

In addition to submitting bids, a buyer can accept the current ask of a seller at any time. Similarly, a seller can accept the current bid of a buyer at any time. For example, if the current ask is $\$ 7.00$ and Buyer 3 raises their ID card, the proctor will say "Buyer 3?" If Buyer 3 responds by saying "Accept $\$ 7.00$, , the proctor will then say, "Buyer 3 accepts $\$ 7.00$."

\section{A trade occurs when a buyer and a seller agree on a price.}

Let us go through an example sequence of bids and asks that lead to a trade:

- Say that Buyer 1 bids $\$ 5.20$

- If Buyer 2 wishes to submit a bid, they must bid $\$ 5.30$ or more. Say that Buyer 2 bids $\$ 5.30$

- Buyer 2's bid of $\$ 5.30$ displaces Buyer 1's bid of $\$ 5.20$; now any new bid must be greater than $\$ 5.30$

- Any buyer, including Buyer 1 or Buyer 2, is free to submit a bid greater than the current bid of $\$ 5.30$

- Say that Seller 1 enters the market by submitting an ask of $\$ 8.70$

- If Seller 2 wishes to submit an ask they must submit an ask of $\$ 8.60$ or less. Say that Seller 2 asks $\$ 8.60$

- Seller 2's ask of $\$ 8.60$ displaces Seller 1's ask of $\$ 8.70$; now any new asks must be less than $\$ 8.60$

- Any seller, including Seller 1 or Seller 2 , is free to submit an ask less than the current ask of $\$ 8.60$

- Say that Seller 3 asks $\$ 7.00$

- Then Buyer 2 accepts the price of $\$ 7.00$

- A trade has occurred

Recall that whenever a trade occurs, the buyer and the seller of the unit in question each receive a commission of $\$ 0.25$. In our example, Buyer 2 and Seller 3 each record the $\$ 7.00$ price in the appropriate column of their record sheet and then move on to their next unit. After a trade occurs, the bid/ask queue is cleared: All buyers and sellers are free to submit new bids and asks at any price.

Each period will conclude when there are no more bids or asks. When there have been no new bids or asks for a spell, the proctor will say, "Going Once, Going Twice..." If there are no new bids or asks, the proctor will then announce, "Period Closed," and the experiment will continue to the next period. Between periods, buyers and sellers should total their earnings for all trades in the period that just ended. When the next period begins, buyers and sellers can only trade units listed on their record sheet for that period.

There will be 4 buyers and 4 sellers. Each buyer has a value of $\$ 17.70$ for 4 units. This means that up to 16 units may be purchased $(4 \times 4=16)$ in each period. Each seller has a cost of $\$ 15.40$. Three sellers have this cost for 4 units; the fourth seller has this cost for 3 units. This means that up to 15 units may be sold $(3 \times 4+1 \times 3=15)$ in each period. 


\section{Summary}

The following points summarize the experiment:

- $\quad$ There will be 4 buyers and 4 sellers

- Each buyer has a value of $\$ 17.70$

(Up to 16 total units may be purchased each period)

- Each seller has a cost of $\$ 15.40$

(Up to 15 total units may be sold each period)

- $\quad$ Buyer'sProfit $=$ Value - PricePaid $+\$ 0.25$ Commission

- Seller'sProfit $=$ PriceReceived - Cost $+\$ 0.25$ Commission

- Raise your ID card to make a bid or an ask

- Bids and asks must be in $\$ 0.10$ increments

- New bids must be greater than the current bid; new asks must be less than the current ask

\section{Conclusion}

This concludes the instructions. You may review the instructions at any point during the experiment. If you have a question that you feel was not adequately answered by the instructions, please raise your hand now. We will begin when there are no questions.

\section{Instructions, Part II}

The experiment will continue exactly as before, except that:

Each buyer still has a value of $\$ 17.70$. However, three buyers now have this value for 4 units; the fourth buyer has this value for 3 units.

Each seller now has a cost of $\$ 15.40$ for 4 units.

This means that up to 15 units may be purchased $(3 \times 4+1 \times 3=15)$ in each period.

This means that up to 16 units may be sold $(4 \times 4=16)$ in each period.

\section{Appendix B. Experiment questionnaire}

\section{Survey}

\section{Experiment ID (Buyer/Seller and Number):}

Age:

\section{Gender:}

\section{Nationality:}

Canadian Other (please specify)

\section{Is English your first (or native) language?}

Yes No (please specify) 
Student Level:

$\begin{array}{lllllllll}1 & 2 & 3 & 4 & 5 & 6 & 7 & 8 & \text { Other (please specify) }\end{array}$

Major(s):

Before today, did you have previous experience bidding in an auction?

Yes No

B1. Survey responses

Below we report summary statistics from responses to our post-experiment survey.

Table B1. Summary of survey responses.

\begin{tabular}{|c|l|l|l|l|l|l|l|}
\hline Treatment & Age & $\begin{array}{c}\text { Student } \\
\text { Level }\end{array}$ & $\begin{array}{c}\text { Male } \\
(\%)\end{array}$ & $\begin{array}{c}\text { Canadian } \\
(\%)\end{array}$ & $\begin{array}{c}\text { English } \\
(\%)\end{array}$ & $\begin{array}{c}\text { Bus/Econ Major } \\
(\%)\end{array}$ & $\begin{array}{c}\text { Auction Experience } \\
(\%)\end{array}$ \\
\hline All & $\mathbf{2 1 . 9}$ & $\mathbf{5 . 3}$ & $\mathbf{5 9}$ & $\mathbf{4 7}$ & $\mathbf{3 7}$ & $\mathbf{3 3}$ & $\mathbf{1 9}$ \\
\hline & $(98 \%)$ & $(99 \%)$ & $(99)$ & $(99)$ & $(99)$ & $(97)$ & $(98)$ \\
\hline Dx1 & $\mathbf{2 2 . 2}$ & $\mathbf{5 . 1}$ & $\mathbf{6 9}$ & $\mathbf{4 4}$ & $\mathbf{4 2}$ & $\mathbf{4 8}$ & $\mathbf{2 2}$ \\
\hline & $(100 \%)$ & $(100 \%)$ & $(100)$ & $(100)$ & $(97)$ & $(97)$ & $(97)$ \\
\hline Dx5 & $\mathbf{2 3 . 5}$ & $\mathbf{6 . 8}$ & $\mathbf{4 7}$ & $\mathbf{3 4}$ & $\mathbf{4 1}$ & $\mathbf{4 4}$ & $\mathbf{1 6}$ \\
\hline & $(94 \%)$ & $(100 \%)$ & $(100)$ & $(100)$ & $(100)$ & $(100)$ & $(100)$ \\
\hline Sx1 & $\mathbf{1 9 . 2}$ & $\mathbf{3 . 3}$ & $\mathbf{5 6}$ & $\mathbf{5 6}$ & $\mathbf{3 8}$ & $\mathbf{1 4}$ & $\mathbf{2 7}$ \\
\hline & $(94 \%)$ & $(100 \%)$ & $(100)$ & $(100)$ & $(100)$ & $(91)$ & $(94)$ \\
\hline Sx5 & $\mathbf{2 1 . 5}$ & $\mathbf{5 . 4}$ & $\mathbf{6 5}$ & $\mathbf{5 5}$ & $\mathbf{2 6 \%}$ & $\mathbf{2 6}$ & $\mathbf{2 6}$ \\
\hline & $(97 \%)$ & $(97 \%)$ & $(97)$ & $(97)$ & $(97)$ & $(97)$ & $(97)$ \\
\hline iDx1 & $\mathbf{2 2 . 9}$ & $\mathbf{5 . 8}$ & $\mathbf{5 9}$ & $\mathbf{4 5}$ & $\mathbf{4 1}$ & $\mathbf{3 1}$ & $\mathbf{6}$ \\
\hline & $(100 \%)$ & $(100 \%)$ & $(100)$ & $(97)$ & $(100)$ & $(100)$ & $(100)$ \\
\hline
\end{tabular}

Notes: Response percentages in parenthesis. Student Level is an integer from 1 to 9 (all postgraduates are assigned 9). English is the percentage of 'Yes' responses to: "Is English your first (or native) language?" Major is the percentage of Economics or Business majors.

\section{Appendix C. Record sheets}

Below we include a copy of the record sheets given to subjects in the experiment. We include one example record sheet for a buyer and one for a seller in the Dx1 treatment.

\section{Record Sheet for Buyer 1}

\begin{tabular}{|c|c|c|c|c|}
\hline Period 1 & \multicolumn{5}{|c|}{} \\
\hline Unit & Value & Price Paid & Commission & Profit on Unit \\
\hline & $\mathbf{( 1 )}$ & $\mathbf{( 2 )}$ & $\mathbf{( 3 )}$ & \\
\hline $\mathbf{1}^{\text {st }}$ & 17.70 & & 0.25 & \\
\hline $\mathbf{2}^{\text {nd }}$ & 17.70 & & 0.25 & \\
\hline $\mathbf{3}^{\text {rd }}$ & 17.70 & & 0.25 & \\
\hline $\mathbf{4}^{\text {th }}$ & 17.70 & & 0.25 & \\
\hline
\end{tabular}


Period 2

\begin{tabular}{|c|c|c|c|c|}
\hline Unit & Value & Price Paid & Commission & Profit on Unit \\
\hline & $\mathbf{( 1 )}$ & $\mathbf{( 2 )}$ & $\mathbf{( 3 )}$ & $(2)+(3)$ \\
\hline $\mathbf{1}^{\text {st }}$ & 17.70 & & 0.25 \\
\hline $\mathbf{2}^{\text {nd }}$ & 17.70 & & 0.25 \\
\hline $\mathbf{3}^{\text {rd }}$ & 17.70 & & 0.25 \\
\hline $\mathbf{4}^{\text {th }}$ & 17.70 & & 0.25 \\
\hline
\end{tabular}

\begin{tabular}{|c|c|c|c|c|}
\hline \multicolumn{5}{|l|}{ Period 3} \\
\hline Unit & Value & Price Paid & Commission & Profit on Unit \\
\hline & (1) & (2) & (3) & $(1)-(2)+(3)$ \\
\hline $1^{\text {st }}$ & 17.70 & & 0.25 & \\
\hline $2^{\text {nd }}$ & 17.70 & & 0.25 & \\
\hline $3^{\text {rd }}$ & 17.70 & & 0.25 & \\
\hline $4^{\text {th }}$ & 17.70 & & 0.25 & \\
\hline
\end{tabular}

\begin{tabular}{|c|c|c|c|c|}
\hline \multicolumn{5}{|l|}{ Period 4} \\
\hline Unit & Value & Price Paid & Commission & Profit on Unit \\
\hline & (1) & (2) & (3) & $(1)-(2)+(3)$ \\
\hline $1^{\text {st }}$ & 17.70 & & 0.25 & \\
\hline $2^{\text {nd }}$ & 17.70 & & 0.25 & \\
\hline $3^{\text {rd }}$ & 17.70 & & 0.25 & \\
\hline $4^{\text {th }}$ & 17.70 & & 0.25 & \\
\hline
\end{tabular}

\section{Period 5}

\begin{tabular}{|c|c|c|c|c|}
\hline Unit & Value & Price Paid & Commission & Profit on Unit \\
\hline & $(\mathbf{1})$ & $\mathbf{( 2 )}$ & $\mathbf{( 3 )}$ & $(2)+(3)$ \\
\hline $\mathbf{1}^{\text {st }}$ & 17.70 & & 0.25 \\
\hline $\mathbf{2}^{\text {nd }}$ & 17.70 & & 0.25 \\
\hline $\mathbf{3}^{\text {rd }}$ & 17.70 & & 0.25 & 0.25 \\
\hline $\mathbf{4}^{\text {th }}$ & 17.70 & & & \\
\hline
\end{tabular}

Name: Total earnings:

\section{Record Sheet for Seller 1}

\begin{tabular}{|c|c|c|c|c|}
\hline Period 1 \\
\hline Unit & Price Received & Cost & Commission & Profit on Unit \\
\hline
\end{tabular}




\begin{tabular}{|c|c|c|c|c|}
\hline & $\mathbf{( 1 )}$ & $\mathbf{( 2 )}$ & $\mathbf{( 3 )}$ & $(1)-(2)+(3)$ \\
\hline $\mathbf{1}^{\text {st }}$ & & 15.40 & 0.25 & \\
\hline $\mathbf{2}^{\text {nd }}$ & & 15.40 & 0.25 & \\
\hline $\mathbf{3}^{\text {rd }}$ & & 15.40 & 0.25 & \\
\hline $\mathbf{4}^{\text {th }}$ & & 15.40 & 0.25 & \\
\hline
\end{tabular}

\begin{tabular}{|c|c|c|c|c|}
\hline Period 2 \\
\hline Unit & Price Received & Cost & Commission & Profit on Unit \\
\hline & $(\mathbf{1})$ & $\mathbf{( 2 )}$ & $\mathbf{( 3 )}$ & $(1)-(2)+(3)$ \\
\hline $\mathbf{1}^{\text {st }}$ & & 15.40 & 0.25 & \\
\hline $\mathbf{2}^{\text {nd }}$ & & 15.40 & 0.25 & \\
\hline $\mathbf{3}^{\text {rd }}$ & & 15.40 & 0.25 & \\
\hline $\mathbf{4}^{\text {th }}$ & & 15.40 & 0.25 & \\
\hline
\end{tabular}

\begin{tabular}{|c|c|c|c|c|}
\hline Period 3 & \multicolumn{3}{|c|}{} \\
\hline Unit & Price Received & Cost & Commission & Profit on Unit \\
\hline & $(\mathbf{1})$ & $\mathbf{( 2 )}$ & $\mathbf{( 3 )}$ & $(2)+(3)$ \\
\hline $\mathbf{1}^{\text {st }}$ & & 15.40 & 0.25 & \\
\hline $\mathbf{2}^{\text {nd }}$ & & 15.40 & 0.25 & \\
\hline $\mathbf{3}^{\text {rd }}$ & & 15.40 & 0.25 & \\
\hline $\mathbf{4}^{\text {th }}$ & & 15.40 & 0.25 & \\
\hline
\end{tabular}

\begin{tabular}{|c|c|c|c|c|}
\hline Period 4 & \multicolumn{3}{|l|}{} \\
\hline Unit & Price Received & Cost & Commission & Profit on Unit \\
\hline & $(\mathbf{1})$ & $\mathbf{( 2 )}$ & $\mathbf{( 3 )}$ & $(1)-(2)+(3)$ \\
\hline $\mathbf{1}^{\text {st }}$ & & 15.40 & 0.25 & \\
\hline $\mathbf{2}^{\text {nd }}$ & & 15.40 & 0.25 & \\
\hline $\mathbf{3}^{\text {rd }}$ & & 15.40 & 0.25 & \\
\hline $\mathbf{4}^{\text {th }}$ & & 15.40 & 0.25 & \\
\hline
\end{tabular}

\begin{tabular}{|c|c|c|c|c|}
\hline Period 5 & \multicolumn{3}{|l|}{} \\
\hline Unit & Price Received & Cost & Commission & Profit on Unit \\
\hline & $\mathbf{( 1 )}$ & $\mathbf{( 2 )}$ & $\mathbf{( 3 )}$ & $(1)-(2)+(3)$ \\
\hline $\mathbf{1}^{\text {st }}$ & & 15.40 & 0.25 & \\
\hline $\mathbf{2}^{\text {nd }}$ & & 15.40 & 0.25 & \\
\hline $\mathbf{3}^{\text {rd }}$ & & 15.40 & 0.25 & \\
\hline $\mathbf{4}^{\text {th }}$ & & 15.40 & 0.25 & \\
\hline
\end{tabular}




\section{References}

Cason, Williams, 1990 T.N. Cason, A.W. Williams. Competitive equilibrium convergence in a postedoffer market with extreme earnings inequities. J. Econ. Behav. Organ., 14 (3) (1990), pp. 331352.

Davis, Holt, 1993 D.D. Davis, C.A. Holt. Experimental Economics, Princeton University Press (1993).

Davis, Holt, 1994 D.D. Davis, C.A. Holt. Market power and mergers in laboratory markets with posted prices. Rand J. Econ., 25 (3) (1994), pp. 467-487.

Davis, Williams, 1990 D.D. Davis, A.W. Williams. Market power and the institutional asymmetry of the posted offer trading institution. Econ. Lett., 34 (3) (1990), pp. 211-214.

Davis, Williams, 1991 D.D. Davis, A.W. Williams. The Hayek hypothesis in experimental auctions: institutional effects and market power. Econ. Inq., 29 (2) (1991), pp. 261-274.

Holt, 1989 C.A. Holt. The exercise of market power in laboratory experiments. J. Law Econ., 32 (2, Part 2) (1989), pp. S107-S130.

Holt, Langan, Villamil, 1986 C.A. Holt, L.W. Langan, A.P. Villamil. Market power in oral double auctions. Econ. Inq., 24 (1) (1986), pp. 107-123.

Jevons, 1871 W.S. Jevons. The Theory of Political Economy, Macmillan and co (1871).

Kachelmeier, Shehata, 1992 S.J. Kachelmeier, M. Shehata. Culture and competition: a laboratory market comparison between china and the west. J. Econ. Behav. Organ., 19 (2) (1992), pp. 145168.

Plott, Smith, 1978 C.R. Plott, V.L. Smith. An experimental examination of two exchange institutions. Rev. Econ. Stud., 45 (1) (1978), pp. 133-153.

Roth, Ockenfels, 2002 A.E. Roth, A. Ockenfels. Last-minute bidding and the rules for ending secondprice auctions: evidence from ebay and amazon auctions on the internet. Am. Econ. Rev., 92 (4) (2002), pp. 1093-1103.

Smith, 1962 V.L. Smith. An experimental study of competitive market behavior. J. Polit. Econ., 70 (2) (1962), pp. 111-137.

Smith, 1965 V.L. Smith. Experimental auction markets and the Walrasian hypothesis. J Polit. Econ., 73 (4) (1965), pp. 387-393.

Smith, 1976a V.L. Smith. Bidding and auctioning institutions: experimental results. Y. Amihud (Ed.), Bidding and Auctioning for Procurement and Allocation, NY: New York University Press, New York (1976), pp. 345-377.

Smith, 1976b V.L. Smith. Experimental economics: induced value theory. Am. Econ. Rev., 66 (2) (1976), pp. 274-279.

Smith, 1980 V.L. Smith. Relevance of laboratory experiments to testing resource allocation theory. J. Kmenta, J.B. Ramsey (Eds.), Evaluation of Econometric Models, Academic Press (1980), pp. 345377.

Smith, 1981 V.L. Smith. An empirical study of decentralized institutions of monopoly restraint. G. Horwich, J.P. Quirk (Eds.), Essays in Contemporary Fields of Economics in Honor of Emanuel T. zweiler, Purdue University Press, West Lafayette (1981), pp. 83-106.

Smith, 1982a V.L. Smith. Markets as economizers of information: experimental examination of the "Hayek hypothesis". Econ. Inq., 20 (2) (1982), pp. 165-179.

Smith, 1982b V.L. Smith. Microeconomic systems as an experimental science. Am. Econ. Rev., 72 (5) (1982), pp. 923-955. 
Smith, Williams, 1982 V.L. Smith, A.W. Williams. The effects of rent asymmetries in experimental auction markets. J. Econ. Behav. Organ., 3 (1) (1982), pp. 99-116.

Smith, Williams, 1990 V.L. Smith, A.W. Williams. The boundaries of competitive price theory: convergence, expectations, and transaction costs. L. Green, J. Kagel (Eds.), Advances in behavioral economics, NJ: Ablex Publishing Company, Norwood (1990), pp. 31-53.

Stigler, 1966 G.J. Stigler. The Theory of Price: Third Edition, The Macmillan Company (1966), p. 89. Williams, 1980 A.W. Williams. Computerized double-auction markets: some initial experimental results. J. Bus., 53 (3) (1980), pp. 235-258.

Wilson, 1998 B.J. Wilson. What collusion? unilateral market power as a catalyst for countercyclical markups. Exp. Econ., 1 (2) (1998), pp. 133-145.

${ }^{2}$ Kimbrough would like to thank the SSHRC Insight Grants Program (435-2015-0798) for funding this research. We would like to thank the editor and two anonymous referees as well as Cary Deck, Heinrich Nax, Vernon Smith, Arlie Williams, Bart Wilson, and participants at the Chapman University Conference in Honor of Vernon Smith's 90th Birthday and the 2017 meetings of the Canadian Economic Association for helpful comments. We would also like to thank Kevin Laughren, Garrett Petersen, and François Reynaud for excellent research assistance and Jeffrey Kirchner of the Economic Science Institute for sharing (and revising) the double auction software. All remaining errors are our own.

${ }^{1}$ Cason and Williams (1990) refer to such a supply and demand environment as an "extreme earnings inequality" design. As we note, this is true of these markets at the CE, but this label is less descriptive of the market configuration than "swastika" design, despite the unfortunate connotations of the latter.

${ }^{2}$ See e.g. the opening quote from Jevons (1871) for the classic statement of the view that complete information is a necessary condition for CE-so necessary that it might justify coercion.

${ }^{3}$ The main institutional difference between these markets was Smith's use of a trading commission.

${ }^{4}$ See Davis and Holt (1994); Davis and Williams (1990), and Wilson (1998) for related work exploring market power in the posted-offer market institution. All three studies show evidence that market power may impede convergence in posted-offer markets.

${ }^{5}$ We chose sessions S1x-S6x from Smith and Williams (1990) (see Table 1) as our baseline because they report tight convergence to the $\mathrm{CE}$ in incomplete information markets with a trading commission. Compare this to sessions S7x and S8x in Smith and Williams (1990) and to Kachelmeier and Shehata (1992) which lack a trading commission and in which markets do not quite converge to the CE.

${ }^{6}$ One of the authors, who has extensive experience conducting classroom double auctions, played the auctioneer role in each session. Every effort was made to ensure that each auction was conducted in a similar fashion to all others. In particular, the soft close rule was implemented as consistently as possible.

${ }^{7}$ When experimental markets became computerized, researchers seem to have switched to using a hard close. In some markets such as Kachelmeier and Shehata (1992), the rule is a hard close with an activity rule than can end a period early if trading activity ceases before the clock expires. Based on our experience, we suspect the main role of the hard close is to encourage buyers and sellers to make offers that are plausibly acceptable to the other side of the market more quickly. 
${ }^{8}$ In addition to unavoidable differences in time, place, and subject pool, we vary four other design features from Smith and Williams (1990). These are, in order of presumed importance: 1) We use hand-run markets as opposed to computerized markets; 2) We permit trading at a loss; 3) We use a "soft" market close; and 4) Our payments are scaled to account for inflation and thus our surplus-tocommission ratio is 0.11 compared to 0.09 . The effect of deviation (1) is unclear. With novice traders, Williams (1980) reports more rapid convergence in hand-run than in computerized double auctions. However, we thank an anonymous referee for noting that novice traders may be more hesitant to submit bids and asks in the former institution, and that in 2017, participants may be more comfortable with computer interfaces than were Williams' (1980) participants. The consequence of (2) is to effectively shift the supply and demand arrays by $\$ 0.25$ (the amount of the commission) and to increase the surplus available in exchange from $\$ 2.30$ to $\$ 2.80$. It is interesting to see whether traders realize this and then aggressively attempt to capture this surplus in the market. If traders capture this surplus, the imposed $\$ 0.10$ price increment means that the effective commission per trade will be only $\$ 0.05$ for those on the relatively abundant side of the market. The impact of (3) is less clear and perhaps merits future research. In the context of single unit, ascending price auctions, a soft close has been shown to increase efficiency by reducing last-second bid "sniping" (Roth and Ockenfels, 2002), but it is unclear to what degree that insight transfers to a multi-unit double auction.

${ }^{9}$ Wilson (1998) compares complete and incomplete information versions of the posted-offer environment with market power studied by Davis and Holt (1994) and shows that incomplete information can sometimes have a hysteresis effect in which prices remain supracompetitive even after market power has been eliminated. Our design does not vary the presence of market power within-subject.

${ }^{10}$ Our analysis is robust to removing controls for $t$ from specification (1) and estimating the resulting model period-by-period.

${ }^{11}$ Recall that we ignore the implicit shifts in the supply and demand curves induced by the $\$ 0.25$ commission for each trader. If we estimate model (1) assuming an equilibrium price $\left(P_{j}^{*}\right)$ that is halfway between 17.70 and 17.90 (15.40 and 15.15), the significance of our results does not change. If we assume that $P_{j}^{*}=17.95$ in our excess demand treatments, we still observe convergence in $D \times 5$ in Period 5, and we still do not observe convergence in any $D x 1$ period. When $P_{j}^{*}=15.15$, we do not observe convergence in any period in $S \times 5$ or $S \times 1$.

${ }^{12}$ While we cannot rule out the possibility that this finding does not extend to computerized, complete information double auctions or to hard-close, complete information double auctions, we suspect that it does.

${ }^{13}$ Compare our design to the supply and demand arrays in Holt et al. (1986) in which 16 units are traded at the CE; withholding 1 unit in our $x 1$ treatments reduces efficiency by $6.67 \%$ vs. a reduction of $4 \%$ from withholding 2 units (consistent with the exercise of market power) in their design.

${ }^{14}$ Note in Fig. 7 that 0 units were traded in period 2 of Session 4 of $S x 5$. If we exclude this period from our efficiency calculation, $\mathrm{S} \times 5$ efficiency was $94 \%$.

${ }^{15}$ Given that we use a linear model, we get efficiency estimates greater than $100 \%$ for some periods in the Dx5 treatment. Since we are not making use of these predicted values elsewhere, we do not view this as a major issue. 
${ }^{16}$ Upon seeing this unfold, the experimenter panicked and wondered if he had handed out paperwork to subjects containing the wrong supply and demand arrays. No such mistake was made.

${ }^{17}$ Note that the division is endogenous to each session and differs across the sessions. This outcome is similar to that observed in the so-called "box" design reported in Smith and Williams (1990), which employs similar supply and demand arrays to our own but has neither excess supply nor excess demand.

${ }^{18}$ There is no relationship between total "activity" (bids plus asks) and efficiency in a trading period. No correlations are significant at the treatment level except for in Dx5. However, because efficiency was less than $100 \%$ just twice in 20 periods, this significant, negative correlation coefficient is suspect.

${ }^{19}$ Holt et al. (1986) and Davis and Williams (1991) both suggest that subject experience may matter for withholding. While none of our subjects had prior laboratory experience in double auctions, we surveyed them about their prior auction experience and their university major. No point-biserial correlations between either earnings and auction experience, or earnings and economics/business major, are significant for any treatment. 